\title{
Cooperativity in Alcohol-Nitrogen Complexes: Understanding Cryomatrices through Slit Jet Expansions
}

\author{
Sönke Oswald, Mareike Wallrabe, and Martin A. Suhm*๑ \\ Institut für Physikalische Chemie, Georg-August-Universität Göttingen, Tammannstraße 6, 37077 Göttingen, Germany
}

Supporting Information

ABSTRACT: FTIR spectroscopy of supersonic expansions is used to characterize alcohol dimers with one, two, and several nitrogen molecules attached to them. The nitrogen coating causes progressive spectral downshifts of the $\mathrm{OH}$ stretching fundamentals which are related to and explain matrix isolation shifts. Comparison of methanol, tert-butyl alcohol and ethanol as well as deuteration of methanol assist in the assignment. Alcohol monomers and trimers are significantly more resistant to nitrogen coating due to a lack of cooperativity and dangling bonds, respectively. In the case of ethanol, the role of conformational isomerism and combination bands is further elucidated. The experimental findings help rationalize the anomalously small $\mathrm{OH}$ stretching dimerization shift of methanol in the gas phase, in comparison to that of tert-butyl alcohol.

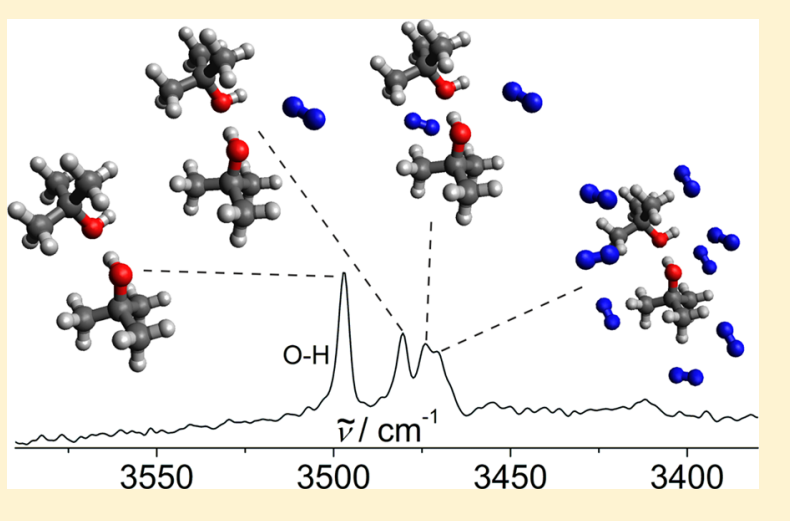

\section{INTRODUCTION}

Matrix isolation FTIR spectroscopy is one of the most powerful and sensitive tools to elucidate the structure and dynamics of transient species and controlled aggregation of organic molecules via hydrogen bonds. ${ }^{1-4}$ It suffers from characteristic spectral shifts and splittings, even for the lightest solid matrices of $\mathrm{pH}_{2}{ }^{5,6}$ and $\mathrm{Ne}$, as well as for helium droplets. ${ }^{8}$ A better understanding of such matrix effects would be advantageous for the use of matrix isolation in delicate applications and rigorous comparison to theoretical predictions. This can be supported by the comparison of cryogenic matrix spectra with those obtained in a stepwise clustering approach. ${ }^{9}$ Molecular nitrogen is known to be a rather strong perturber when used as a matrix isolation host, ${ }^{2,10}$ probably due to its significant quadrupole moment $^{11}$ of $-5.0(2) \times 10^{-40} \mathrm{C} \mathrm{m} \mathrm{m}^{2}$ with negative partial charges at the ends of the molecule and a positive partial charge in its center. The interaction is much more specific than for a quadrupole-free argon host. ${ }^{12}$ Nitrogen is actually used to experimentally characterize the acidity strength of zeolites based on the $\mathrm{OH}$ stretching shift upon adsorption, although the correlation between spectral shift and binding energy is controversial. ${ }^{13}$ Therefore, it makes sense to initiate a systematic investigation of matrix shifts by studying stepwise nitrogen coating of simple hydrogen-bonded aggregates. An important question is whether the effect of the nitrogen units attached to the solute is simply additive or rather cooperative. ${ }^{14,15}$ Vibrational spectroscopy is sensitive to such cooperative effects. Alcohols are suitable matrix guests, because their size, donor quality ${ }^{16}$ and conformational diversity ${ }^{10}$ can be tuned. ${ }^{17}$ This is important, because the interpretation of subtle effects rests on systematic trends rather than isolated findings. To illustrate the situation, Table 1 lists ranges of
Table 1. Experimental Nitrogen Matrix Isolation Downshifts, $\Delta \tilde{\nu}_{\mathrm{mi}}{ }^{2,4,10,18-24}$ Relative to Jet-Cooled Band Centers ${ }^{6,25-30}$ for the $\mathrm{OH}$ Stretching Fundamental of the Studied Alcohol Aggregates $^{a}$

\begin{tabular}{llc} 
& \multicolumn{2}{c}{$-\Delta \tilde{\nu}_{\mathrm{mi}} / \mathrm{cm}^{-1}$} \\
\cline { 2 - 3 } structure & range & best estimate \\
\cline { 2 - 3 } $\mathrm{M}$ & $20-25$ & $\mathbf{2 1}$ \\
$M \mathrm{M}$ & $16-33$ & $\mathbf{2 4}$ \\
$\mathrm{M} M$ & $55-86$ & $\mathbf{7 1}$ \\
$\mathrm{B}$ & $13-14$ & $\mathbf{1 3}$ \\
$\mathrm{BB}$ & $(-4)-72$ & $\approx \mathbf{2 7}$ \\
$\mathrm{E}$ & $10-25$ & - \\
$\mathrm{EE}$ & $0-37$ & - \\
$\mathrm{E} E$ & $14-78$ & -
\end{tabular}

${ }^{a_{T}}$ The studied compounds are abbreviated with $\mathrm{M}$ (methanol), B (tertbutyl alcohol), and E (ethanol). To describe cluster composition, these single letters are repeated according to the number of units present in donor-acceptor sequence. Roman structure symbols denote the monomer unit involved in the vibration, italic symbols the passive monomer. Somewhat subjective best estimates for the actual downshift by looking at dominant sites or assignments are added in bold for $\mathrm{M}$ and B. See Table S1 in the Supporting Information for details

observed ${ }^{2,4,10,18-24}$ nitrogen (N) matrix isolation downshifts from experimental jet-cooled $\mathrm{OH}$ stretching band centers ${ }^{6,25-30}$ for methanol (M), tert-butyl alcohol (B), and ethanol (E). These ranges are quite broad, mostly due to matrix site splittings and conformational isomerism (in the case of

Received: February 8, 2017

Revised: $\quad$ March 30, 2017

Published: April 26, 2017 
ethanol). We also present our tentative best matrix downshift estimate for preferred assignments and dominant sites in bold face for methanol and tert-butyl alcohol. Table S1 in the Supporting Information provides a more detailed listing including the band positions, also highlighting dominant sites. In the vibration label, we distinguish vibrating monomer units by Roman case and write passive (almost nonvibrating) monomer units in Italic case. Even in the coarse-grained Table 1 , one can see that the average matrix embedding effect typically more than doubles when moving from alcohol monomers to dimer donors, thus hinting at substantial cooperativity between $\mathrm{OHO}$ and $\mathrm{OHN}$ hydrogen bonding, in particular for methanol. The table entries are limited to a selection of earlier and more recent matrix isolation studies. Different band centers for ethanol monomers and dimers have recently been obtained in nitrogen matrices by a grating instrument, ${ }^{31}$ although the guest/host-ratio is somewhat too high and the signal-to-noise ratio is somewhat too low for robust dimer assignments and therefore the values from refs 10 and 18 are considered more reliable (we also note that the band centers assigned to $\mathrm{E}$ and its aggregates based on refs 25, 32, and 33 are actually in part incorrectly cited in that work).

A side benefit of studying nitrogen is its dominance in the atmosphere. Inorganic and organic molecules in cold stratospheric regions will therefore frequently collide with nitrogen molecules, forming transient complexes. The vacuum isolation and stabilization of these transient complexes in supersonic jets enhances our understanding of such nonreactive collisions and their spectral signature with possible implications on the radiation balance of our planet, at least for the case of water. ${ }^{34}$

Competition to weak nitrogen complexation from hydrogen bond mediated self-aggregation of alcohols is strong. This calls for a sensitive spectroscopic approach which tolerates for extreme dilution of the alcohols to suppress their progressive aggregation, while still allowing for stepwise nitrogen decoration through a controlled excess of nitrogen in the expansion. The long slit-jet FTIR spectrometer described earlier $^{35}$ is well suited for this project. As it does not provide size selectivity in contrast to some kinds of action spectrosco$\mathrm{py}^{27,36}$ spectral interpretation profits substantially from assisting quantum chemical calculations. The dispersion corrected $^{37}$ B3LYP hybrid functional in combination with a large basis set has been shown to provide a reasonably accurate description of weak hydrogen bonding in terms of structures and harmonic vibrations. ${ }^{6}$ On top of this, relative energy comparisons at $\operatorname{CCSD}(\mathrm{T})$ level should be even more reliable. ${ }^{12}$ In contrast, MP2 calculations do not offer an appropriate cost/ performance ratio for nitrogen complexes.

In the next sections, we describe the experimental and computational methods, followed by a presentation and interpretation of helium expansion spectra for methanol, the more bulky tert-butyl alcohol and the conformationally ambiguous ethanol, all with different extents of nitrogen admixture. We conclude after a discussion of the alcohol trends in the spectral signatures, which supports the spectral assignments. As a byproduct, we discuss why the $\mathrm{OH}$ stretching dimerization downshifts of methanol and tert-butyl alcohol are similar in nitrogen matrices and in harmonic quantum chemical predictions but are quite different in the gas phase experiment.

\section{EXPERIMENTAL DETAILS}

Methanol- $d_{0}$ (Sigma-Aldrich, 99.98\%), methanol- $d_{1}$ (euriso-top, 99.0\% D), tert-butyl alcohol (Roth, 99\%), ethanol (Sigma-
Aldrich, 99.8\%), argon (Linde, 99.999\%), and nitrogen (Linde, 99.999\%) were used without further purification to prepare binary and ternary gas mixtures with a large excess of helium (Linde, 99.996\%) as carrier gas.

These gas mixtures (optimized by trial and error for desired average clustering conditions; $\mathrm{N}$ varied from 1 over $2-3$ to $15 \%)$ are introduced via magnetically controlled valves into a $67 \mathrm{~L}$ Teflon-coated reservoir at a stagnation pressure of 0.75 bar and expanded through six magnetic valves into a preexpansion chamber from which the gas escapes through a $600 \times 0.2 \mathrm{~mm}^{2}$ slit nozzle into a vacuum chamber. The resulting supersonic jet expansion is probed by a Bruker IFS $66 \mathrm{v} / \mathrm{S}$ FTIR spectrometer at $2 \mathrm{~cm}^{-1}$ resolution that is provided with a $150 \mathrm{~W}$ tungsten lamp, $\mathrm{CaF}_{2}$ optics, and a liquid nitrogen cooled $3 \mathrm{~mm}^{2}$ InSb detector. A sufficiently low background pressure in the vacuum chamber is maintained by an attached $23 \mathrm{~m}^{3}$ buffer volume. The volume is continuously evacuated by a series of Roots pumps at a speed of up to $2500 \mathrm{~m}^{3} \mathrm{~h}^{-1}$. A delay of at least $25 \mathrm{~s}$ between two magnetic valve pulses of 147 $\mathrm{ms}$ duration ensures that the vacuum has time to recover. Spectra are averaged from about 300 to 650 gas pulses. A detailed description of the infrared setup (filet-jet) may be found elsewhere. ${ }^{35}$

\section{QUANTUM CHEMICAL CALCULATIONS AND NOMENCLATURE}

The studied compounds are abbreviated with $\mathrm{N}$ (nitrogen), $\mathrm{M}$ (methanol), B (tert-butyl alcohol), and E (ethanol). To describe cluster composition, these single letters are repeated according to the number of units present in donor-acceptor direction. A subscript to the $\mathrm{N}$ marks the alcohol backbone atom type $(\mathrm{C}, \mathrm{O}, \mathrm{H})$ to which the nitrogen molecule is closest. Thus, $\mathrm{MMN}_{\mathrm{H}}$ denotes a nitrogen molecule coordinating the acceptor $\mathrm{OH}$ group in a methanol dimer. A tetramer built from a methanol dimer which is coordinated on the methanol donor oxygen and the methanol acceptor hydrogen atom is referred to as $\mathrm{N}_{\mathrm{O}} \mathrm{MMN}_{\mathrm{H}}$. More completely and unspecifically nanosolvated species are indicated by parentheses, so the nitrogen nanosolvated ethanol dimer is denominated $(\mathrm{EE}) \mathrm{N}$. In the case of ethanol, the conformation is specified as $t, g-$, or $g+$, where appropriate. For ethanol dimers, the enantiomer in which the donor coordinates the right lone electron pair of the acceptor oxygen is always chosen. ${ }^{30}$

Quantum chemical studies for the exploration of local minima are executed with the Gaussian 09 Revision D.01 ${ }^{38}$ program package with the dispersion-corrected (D3) ${ }^{37}$ B3LYP functional, which implies the application of Becke-Johnson damping (BJ), ${ }^{39}$ and augmented correlation-consistent basis sets (in most cases aug-cc-pVTZ, in short aVTZ). Significant differences to version E.01 due to a more robust implementation of Becke-Johnson damping are restricted to soft modes below $50 \mathrm{~cm}^{-1}$ and resulting zero-point energy variations on the order of $0.1 \mathrm{~kJ} \mathrm{~mol}^{-1}$. The exploration of the local minima was not exhaustive for the more weakly bound structures, but systematic enough to find the most stable isomers. In selected cases, anharmonic vibrational analysis is performed with second order vibrational perturbation theory (VPT2) $)^{40}$ for B3LYP calculations (Revision E.01). Numerical noise is minimized by employing very tight optimization criteria (opt = verytight) and the superfine integration grid (int $=$ SuperFine) in Gaussian. B3LYP optimizations are complemented by $\operatorname{CCSD}(\mathrm{T}) / \mathrm{aVTZ}$ single-point energies. To assess the potential accuracy of these single point calculations, small components (N, M, MM) are 
Table 2. Experimental and Theoretically Predicted Anharmonic $(\tilde{\nu})^{a}$ and Harmonic $\left(\omega_{\mathrm{e}}\right)$ Stretching Band Center Positions as Well as Diagonal Anharmonicity Constants $\left(\omega_{\mathrm{e}} x_{\mathrm{e}}\right)^{a}$ in $\mathrm{cm}^{-1}$ for Molecular Nitrogen (N), Methanol (M) and the Methanol Dimer Donor (MM)

\begin{tabular}{|c|c|c|c|c|c|c|c|c|c|}
\hline & \multicolumn{3}{|c|}{$\mathrm{N}$} & \multicolumn{3}{|c|}{ M } & \multicolumn{3}{|c|}{$\mathrm{MM}$} \\
\hline & $\tilde{\nu}$ & $\omega_{e}$ & $\omega_{e} x_{e}$ & $\tilde{\nu}$ & $\omega_{e}$ & $\omega_{e} x_{e}$ & $\tilde{\nu}$ & $\omega_{e}$ & $\omega_{e} x_{e}$ \\
\hline reference & $2329.91^{43}$ & $2358.57^{44}$ & $14.33^{44}$ & $\begin{array}{r}3685^{6} \\
3683^{46}\end{array}$ & $\begin{array}{c}(3857)^{f} \\
3863^{45}\end{array}$ & $86^{6}$ & $3575^{6}$ & $(3773)^{f} / 3742^{45}$ & $99^{6}$ \\
\hline $\operatorname{LCCSD}(T)^{b}$ & - & 2354 & - & - & 3862 & - & - & 3740 & - \\
\hline $\operatorname{CCSD}(\mathrm{T})^{c}$ & - & 2343 & - & - & 3844 & - & - & - & - \\
\hline $\mathrm{B} \mathrm{LYP}^{d}$ & 2422 & 2447 & 13 & 3654 & 3829 & 85 & 3483 & 3653 & 105 \\
\hline $\mathrm{MP} 2^{e}$ & 2149 & 2187 & 19 & 3687 & 3860 & 82 & 3553 & 3695 & 108 \\
\hline
\end{tabular}

${ }^{a}$ VPT2, Gaussian 09, E.01. ${ }^{b} \mathrm{LCCSD}\left(\mathrm{T}^{*}\right)$-F12/VDZ-F12(int). ${ }^{c} \mathrm{CCSD}(\mathrm{T}) / \mathrm{aVTZ} .{ }^{d} \mathrm{~B} 3 \mathrm{LYP}-\mathrm{D} 3(\mathrm{BJ}) / \mathrm{aVTZ} .{ }^{e} \mathrm{MP} 2 / \mathrm{aVTZ} .{ }^{f_{\text {Formal }}}$ one-dimensional Morse model harmonic wavenumber from experimental $\mathrm{OH}$ overtone analysis.

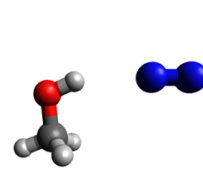

(a) $\mathrm{MN}_{\mathrm{H}}$

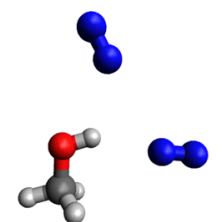

(b) $\mathrm{MN}_{\mathrm{H}} \mathrm{N}_{\mathrm{H}}$

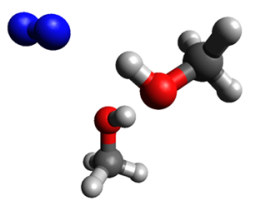

(c) $\mathrm{MMN}_{\mathrm{H}}$

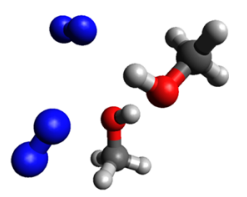

(d) $\mathrm{MMN}_{\mathrm{H}} \mathrm{N}_{\mathrm{H}}$

Figure 1. Most stable structures of mixed methanol-nitrogen aggregates optimized at the B3LYP-D3(BJ)/aVTZ level.

subjected to geometry optimization and harmonic frequency calculations at $\operatorname{CCSD}(\mathrm{T})$ or explicitly correlated local CCSD(T) (LCCSD(T*)-F12/VDZ-F12(int)) level. The latter are carried out with the MOLPRO 2012.1 program package. ${ }^{41}$ The results for $\mathrm{N}, \mathrm{M}$ and $\mathrm{MM}$ summarized in Table 2 indicate the quality of $\operatorname{CCSD}(\mathrm{T})$ predictions, whereas $\mathrm{MP} 2$ and B3LYP have somewhat different deficiencies. The basis set dependence of canoncial $\operatorname{CCSD}(\mathrm{T})$ calculations is also explored for $\mathrm{N}$. The $\operatorname{CCSD}(\mathrm{T}) / \mathrm{aVQZ}$ and $\operatorname{CCSD}(\mathrm{T}) / \mathrm{aV} 5 \mathrm{Z}$ results for the harmonic stretching wavenumber almost match the experimental value of $2358.57 \mathrm{~cm}^{-1}$ with 2358 and $2357 \mathrm{~cm}^{-1}$, respectively although the basis set limit ${ }^{42}$ is $2363 \mathrm{~cm}^{-1}$.

Anharmonic vibrational calculations are not considered essential for the assignment of the mixed clusters, ${ }^{40}$ as the change in anharmonicity upon $\mathrm{N}$ complexation is relatively small, but still larger than for $\mathrm{Ne}$ and $p \mathrm{H}_{2}$ hosts. ${ }^{6}$ They are only consulted to characterize the quality of the electronic structure calculations for the constituents. Furthermore, anharmonic spectral predictions are much more dependent on the employed revision of Gaussian 09 as shown in Table S3 available in the Supporting Information and generally often include physically unreasonable results, especially for soft modes below $50 \mathrm{~cm}^{-1}$. Since these deviations are comparable in size to the anharmonic $\mathrm{OH}$ stretching shift corrections, the focus in the following sections will be on harmonic results.

\section{RESULTS AND DISCUSSION}

Methanol-Nitrogen Complexes. The most stable conformations of mixed methanol-nitrogen complexes with one or two molecules of each type are depicted in Figure 1. All stable structures found in this study are displayed in Figure S1 in the Supporting Information.

Three different stable conformations of $\mathrm{MN}$ are predicted theoretically (Figure S1). In the most stable conformation (Figure 1) a weak hydrogen bond is formed between the $\mathrm{OH}$ group and a negative end of $\mathrm{N}$. $\mathrm{N}$ can also bind to an oxygen lone pair via its positively polarized center or dispersion-driven aggregation to the $\mathrm{CH}_{3}$ group can occur. The respective binding sites are denoted as subscripts at the respective N. Five different MNN conformations are found (Figure S1), which basically are combinations of the different binding sites observed in $\mathrm{MN}$. Cooperative effects on the $\mathrm{OH}$ stretching vibration are not predicted (Table 3 ).

Four possible conformers are found for $\mathrm{MMN}$ as depicted in Figure $\mathrm{S} 1$. In the most stable one $\left(\mathrm{MMN}_{\mathrm{H}}\right.$, Figure 1$), \mathrm{N}$ is hydrogen-bonded to the acceptor $\mathrm{OH}$ group and additionally stabilized by interactions with the donor oxygen lone pairs, effectively forming a ring-like topology of the two $M$ oxygens and $\mathrm{N}$. The possibility of $\mathrm{N}$ attached to an oxygen lone pair of the proton donor or acceptor exists as well $\left(\mathrm{N}_{\mathrm{O}} \mathrm{MM}, \mathrm{MMN}_{\mathrm{O}}\right)$. Dispersion-driven aggregation to the $\mathrm{CH}_{3}$ group $\left(\mathrm{MMN}_{\mathrm{C}}\right)$ is also possible, but far less stable.

Five stable conformations are found for MMNN and depicted in Figure S1. The ring-like topology from $\mathrm{MMN}_{\mathrm{H}}$ is retained in the energetically favored ones, only the binding site of the second $\mathrm{N}$ varies. In the most stable conformation $\left(\mathrm{MMN}_{\mathrm{H}} \mathrm{N}_{\mathrm{H}}\right.$, Figure 1), a weak hydrogen bond with the $\mathrm{MM}$ acceptor $\mathrm{OH}$ hydrogen is formed, in the less stable conformations the second $\mathrm{N}$ is bound at the donor $\left(\mathrm{N}_{\mathrm{O}} \mathrm{MMN}_{\mathrm{H}}\right)$ and acceptor $\left(\mathrm{MMN}_{\mathrm{H}} \mathrm{N}_{\mathrm{O}}\right)$ oxygen, respectively. A structure with both $\mathrm{N}$ molecules attached to the respective oxygen atoms $\left(\mathrm{N}_{\mathrm{O}} \mathrm{MMN} \mathrm{N}_{\mathrm{O}}\right)$ is found as well. The least stable conformation again features aggregation at one of the $\mathrm{CH}_{3}$ groups. Harmonic spectral predictions for all considered clusters are summarized in Table 3.

From a coarse-graining perspective, it is seen that the predicted effect of acceptor $\mathrm{N}_{\mathrm{H}}$ coordination on the acceptor $\mathrm{OH}$ vibration in $\mathrm{MM}$ is rather uniform around $15-20 \mathrm{~cm}^{-1}$, independent of further $\mathrm{N}$ coordination in any position, whereas $\mathrm{N}$ coordination of isolated $\mathrm{M}$ is spectrally unimpressive. For the donor $\mathrm{OH}$ mode, the basic shift for acceptor $\mathrm{N}_{\mathrm{H}}$ coordination is 20-25 $\mathrm{cm}^{-1}$, but double $\mathrm{N}_{\mathrm{H}}$ coordination or push-pull coordination like in $\mathrm{N}_{\mathrm{O}} \mathrm{MMN}_{\mathrm{H}}$ leads to a significant shift increase to $30-35 \mathrm{~cm}^{-1}$ for this mode. The shifts are 
Table 3. Theoretically Predicted Harmonic $\left(\omega_{\mathrm{e}}\right) \mathrm{OH}$ Stretching Band Center Positions and Integrated Infrared Band Strengths $S_{\omega}$ of Methanol and Methanol-Nitrogen Aggregates $^{a}$ Obtained at the B3LYP-D3(BJ)/aVTZ Level

\begin{tabular}{|c|c|c|c|}
\hline structure & $\omega_{e} / \mathrm{cm}^{-1}$ & $S_{\omega} / \mathrm{km} \mathrm{mol}^{-1}$ & $\Delta \omega_{e} / \mathrm{cm}^{-1 b}$ \\
\hline M & 3829 & 31 & - \\
\hline $\mathrm{MN}_{\mathrm{H}}$ & 3831 & 103 & 2 \\
\hline $\mathrm{MN}_{\mathrm{O}}$ & 3830 & 31 & 1 \\
\hline $\mathrm{MN}_{\mathrm{C}}$ & 3829 & 33 & 0 \\
\hline $\mathrm{MN}_{\mathrm{H}} \mathrm{N}_{\mathrm{H}}$ & 3829 & 98 & 0 \\
\hline $\mathrm{N}_{\mathrm{O}} \mathrm{MN}_{\mathrm{H}}$ & 3831 & 137 & 2 \\
\hline $\mathrm{N}_{\mathrm{O}} \mathrm{N}_{\mathrm{O}} \mathrm{M}$ & 3830 & 32 & 1 \\
\hline $\mathrm{MN}_{\mathrm{H}} \mathrm{N}_{\mathrm{C}}$ & 3830 & 84 & 1 \\
\hline $\mathrm{N}_{\mathrm{O}} \mathrm{MN}_{\mathrm{C}}$ & 3830 & 33 & 1 \\
\hline$M \mathrm{M}$ & 3825 & 42 & - \\
\hline$M \mathrm{MN}_{\mathrm{H}}$ & 3807 & 129 & -18 \\
\hline $\mathrm{N}_{\mathrm{O}} \mathrm{MM}$ & 3827 & 42 & 2 \\
\hline$M M_{\mathrm{O}}$ & 3823 & 44 & -2 \\
\hline $\mathrm{MMN}_{\mathrm{C}}$ & 3826 & 44 & 1 \\
\hline$M \mathrm{MN}_{\mathrm{H}} \mathrm{N}_{\mathrm{H}}$ & 3810 & 78 & -15 \\
\hline $\mathrm{N}_{\mathrm{O}} M \mathrm{MN}_{\mathrm{H}}$ & 3809 & 84 & -16 \\
\hline$M M N_{H} \mathrm{~N}_{\mathrm{O}}$ & 3806 & 130 & -19 \\
\hline $\mathrm{N}_{\mathrm{O}} M \mathrm{MN}_{\mathrm{O}}$ & 3824 & 43 & -1 \\
\hline$M M_{\mathrm{H}} \mathrm{N}_{\mathrm{C}}$ & 3807 & 115 & -18 \\
\hline $\mathrm{MM}$ & 3653 & 551 & - \\
\hline $\mathrm{MMN}_{\mathrm{H}}$ & 3629 & 552 & -24 \\
\hline $\mathrm{N}_{\mathrm{O}} \mathrm{MM}$ & 3645 & 551 & -8 \\
\hline $\mathrm{M} M \mathrm{~N}_{\mathrm{O}}$ & 3650 & 521 & -3 \\
\hline $\mathrm{M} M \mathrm{~N}_{\mathrm{C}}$ & 3649 & 560 & -4 \\
\hline $\mathrm{M} M \mathrm{~N}_{\mathrm{H}} \mathrm{N}_{\mathrm{H}}$ & 3618 & 534 & -35 \\
\hline $\mathrm{N}_{\mathrm{O}} \mathrm{MMN} \mathrm{N}_{\mathrm{H}}$ & 3622 & 519 & -31 \\
\hline $\mathrm{MMN}_{\mathrm{H}} \mathrm{N}_{\mathrm{O}}$ & 3629 & 509 & -24 \\
\hline $\mathrm{N}_{\mathrm{O}} \mathrm{M} M \mathrm{~N}_{\mathrm{O}}$ & 3642 & 523 & -11 \\
\hline$M M N_{H} \mathrm{~N}_{\mathrm{C}}$ & 3630 & 538 & -23 \\
\hline
\end{tabular}

${ }^{a}$ Roman M symbols denote the methanol monomer unit involved in the vibration; italic symbols, the passive monomer. ${ }^{b}$ Spectral harmonic shifts relative to the corresponding vibration in the pure methanol fragments.

accompanied by quite substantial IR intensity enhancements (Table 3).

The $\mathrm{OH}$ stretching spectrum of $\mathrm{M}$ clusters is well characterized. ${ }^{26,33}$ Interconversion between five open-chain conformers of $\mathrm{MM}$ and site splitting of the dimer bands are observed in a $\mathrm{N}$ cryomatrix. ${ }^{22}$ FTIR jet spectra of $\mathrm{M}$ and $\mathrm{N}$ coexpanded in helium are shown in Figure 2. In addition to the well-known band positions of $\mathrm{M}$ and its homoaggregates, two new features arise upon addition of $2.5 \% \mathrm{~N}$, downshifted from the MM donor vibration at 3543 and $3534 \mathrm{~cm}^{-1}$, indicating $\mathrm{N}$ coordination of MM. Since both signals are also visible with methanol- $d_{1}$ at 2616 and $2608 \mathrm{~cm}^{-1}$, 30\% less downshifted from the dimer at $2637 \mathrm{~cm}^{-1}$ than in methanol- $d_{0}$, resonances with dark states can be excluded as the cause of this doublefeature. This strongly hints at different cluster compositions or $\mathrm{N}$ coordination numbers such as MMN and MMNN as the cause for the two peaks. The monomer and trimer signals are not influenced significantly by $\mathrm{N}$ addition.

With a large excess of $\mathrm{N}$, such as $15 \%$, a broad band centered at $3512 \mathrm{~cm}^{-1}$ grows in, originating from more completely nanocoated MM. The monomer band develops an additional shoulder at $3663 \mathrm{~cm}^{-1}$, probably caused by the shifted acceptor $\mathrm{OH}$ of various $\mathrm{N}$-coordinated $\mathrm{MM}$. The cluster calculations predict that as long as the acceptor is coordinated by at least one $\mathrm{N}_{\mathrm{H}}$ there is little spectral evolution of this band with increasing coordination. This superposition enhances the visibility of the weak acceptor $\mathrm{OH}$ stretching mode. The shoulder might also have contributions from $\mathrm{N}$-coated $\mathrm{M}$, but the cluster calculations do not support such a substantial Ncoating effect. In general, the harmonic shift predictions are quantitatively somewhat too low, but qualitatively in good agreement with the experimental observations.

If one analyses the gas-to-matrix shift for $\mathrm{M}, \mathrm{MM}$ and larger clusters, the dimer shift is seen to be particularly large. This has already been noted 60 years ago for the shift from $\mathrm{CCl}_{4}$ solution to $\mathrm{N}$ matrix isolation ${ }^{2}$ but was poorly understood at the time, in the absence of appropriate structural and cooperativity models. Our stepwise matrix isolation approach clearly reveals a strong interaction of the $\mathrm{OH}$ group with the first $\mathrm{N}$ molecule as the reason for this pronounced shift, but only when the $\mathrm{OH}$ group is polarized by another $\mathrm{OH}$ group and still available for coordination in a noncyclic structure.

Paradoxically, this cooperative effect brings harmonic density functional predictions for the dimerization shift in MM (-150 to $\left.-180 \mathrm{~cm}^{-1}\right)$ in much better agreement with $\mathrm{N}$ matrix isolation (about $-160 \mathrm{~cm}^{-1}$ ) than with experimental gas phase data (about $-110 \mathrm{~cm}^{-1}$ ), but higher order electron correlation (about $-120 \mathrm{~cm}^{-1}$ for the harmonic shift) clearly shows that this is a consequence of error compensation. ${ }^{45}$ We will argue later on that another source for the large discrepancy between gas phase experiment and harmonic density functional predictions is off-diagonal anharmonicity in the floppy MM system. For this, we have to turn to the less floppy tert-butyl alcohol complexes.

tert-Butyl Alcohol-Nitrogen Complexes. The most stable conformations of mixed tert-butyl alcohol-nitrogen complexes with one or two molecules of each type are depicted in Figure 3. All stable structures found in this study are displayed in Figure S2 in the Supporting Information.

Four stable conformers of $\mathrm{BN}$ were located theoretically (Figure S2). In analogy to $\mathrm{MN}, \mathrm{N}$ is able to bind to an oxygen lone pair via its positively charged center. It can also be attached to either one methyl group or even all three by dispersion interactions or it features a weak hydrogen bond between its negative end and the $\mathrm{OH}$ group of the alcohol. The latter again results in the most stable conformation (Figure 3). Five stable conformations are found for BNN in close analogy to MNN.

For the BBN trimers three different stable conformations are found as depicted in Figure S2. The most stable one $\left(\mathrm{BBN}_{\mathrm{H}}\right.$, Figure 3) features the same ring-like structure as $\mathrm{MMN}_{\mathrm{H}}$. Two less stable conformers exist, in which $\mathrm{N}$ is attached to the oxygen of the donor $\left(\mathrm{N}_{\mathrm{O}} \mathrm{BB}\right)$ or the acceptor $\left(\mathrm{BBN}_{\mathrm{O}}\right) \mathrm{OH}$ group. $\mathrm{BBN}_{\mathrm{C}}$ trimers stabilized by dispersion interactions are higher in energy and the aggregation has nearly no influence on the $\mathrm{OH}$ stretching vibration (Table 4).

Four possible structures are found for BBNN and depicted in Figure S2. Similar to $\mathrm{MMNN}$, the ring-like topology $\mathrm{BBN}_{\mathrm{H}}$ forms the core of the three most stable ones and the additional $\mathrm{N}$ is either attached to the acceptor hydrogen $\left(\mathrm{BBN}_{\mathrm{H}} \mathrm{N}_{\mathrm{H}}\right)$, the oxygen of the donor $\left(\mathrm{N}_{\mathrm{O}} \mathrm{BBN}_{\mathrm{H}}\right)$ or the acceptor $\mathrm{O}\left(\mathrm{BBN}_{\mathrm{H}} \mathrm{N}_{\mathrm{O}}\right)$. The energies of these structures are rather similar, whereas for $M$, there was a clear stability advantage for double $N_{H}$ coordination of the acceptor. Additionally, a less stable structure with both $\mathrm{N}$ molecules attached to the different 


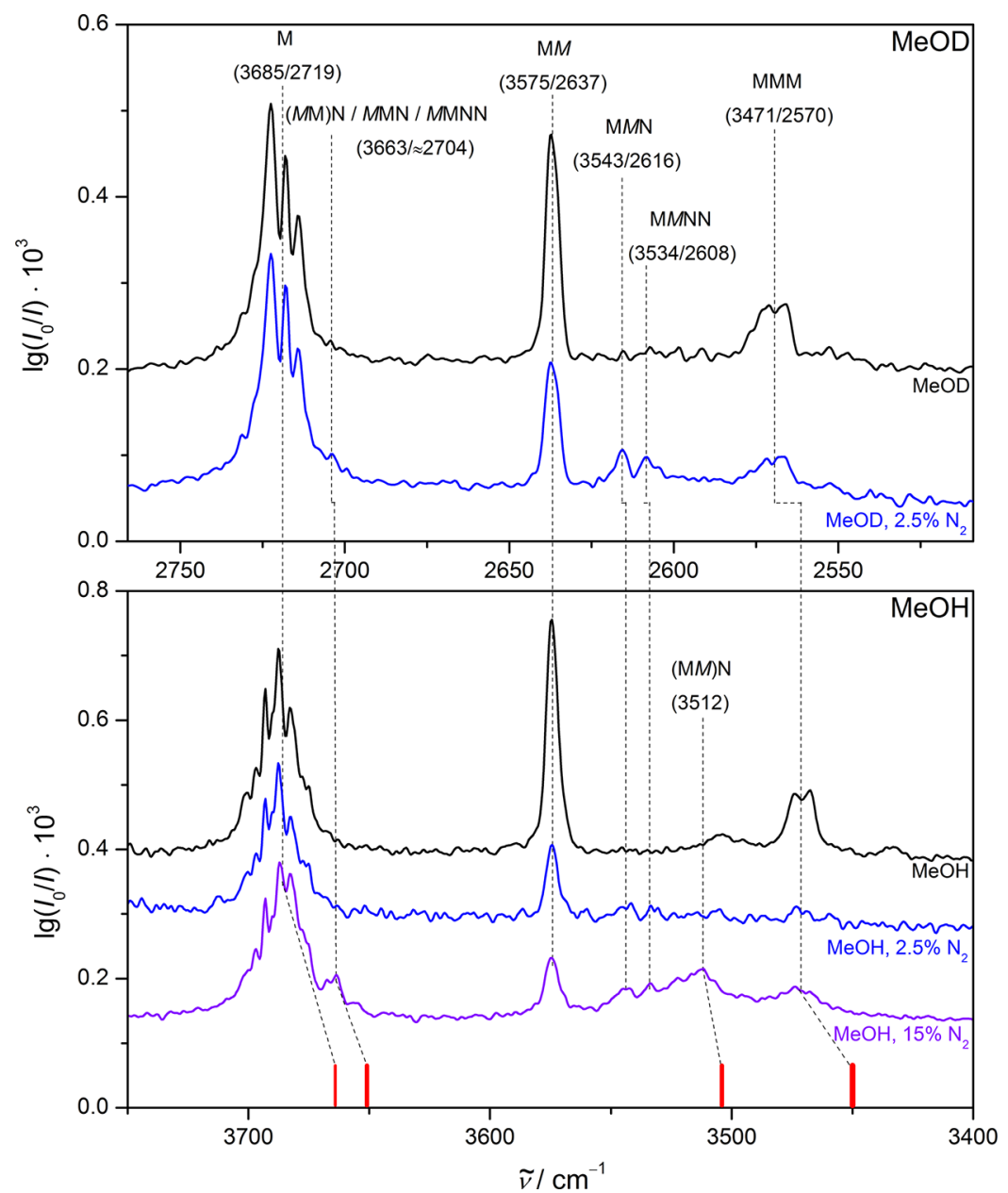

Figure 2. FTIR jet spectra of methanol- $d_{1}$ (upper box) and methanol- $d_{0}$ (lower box) expanded in helium (black traces), $2.5 \%$ nitrogen in helium (blue traces, methanol- $d_{0}$ spectrum scaled by a factor of 2 ) and $15 \%$ nitrogen in helium (violet trace). The wavenumber scales are stretched and shifted such that the monomer and methanol dimer signals match for the two isotopologues. Red bars at the bottom indicate the most dominant signals in a nitrogen matrix taken from refs 4,20 , and 22 . Labels and wavenumbers for (tentative) assignments are provided.

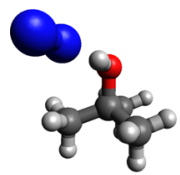

(a) $\mathrm{BN}_{\mathrm{H}}$

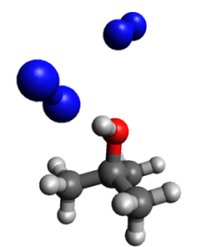

(b) $\mathrm{BN}_{\mathrm{H}} \mathrm{N}_{\mathrm{H}}$

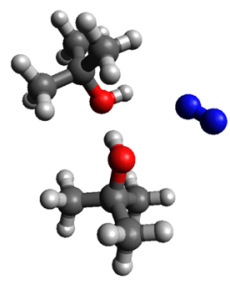

(c) $\mathrm{BBN}_{\mathrm{H}}$

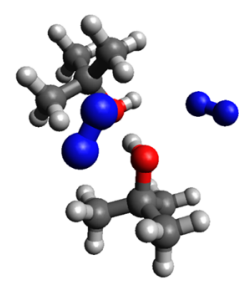

(d) $\mathrm{N}_{\mathrm{O}} \mathrm{BBN}_{\mathrm{H}}$

Figure 3. Most stable structures for each composition of mixed tert-butyl alcohol-nitrogen aggregates optimized at the B3LYP-D3(BJ)/aVTZ level.

oxygen atoms $\left(\mathrm{N}_{\mathrm{O}} \mathrm{BBN}_{\mathrm{O}}\right)$ is found. Spectral predictions for all considered clusters are summarized in Table 4.

The $\mathrm{OH}$ stretching spectra of pure $\mathrm{B}$ clusters $^{28}$ and $\mathrm{B}$ trapped in $\mathrm{N}$-matrices ${ }^{23}$ are well-known. Figure 4 shows FTIR spectra of $\mathrm{B}$ and $\mathrm{N}$ coexpansions. In case of an excess of $15 \% \mathrm{~N}$ in the expansion a broad band centered at $3469 \mathrm{~cm}^{-1}$ can be found, generated by nanocoated BB. It agrees quite closely with corresponding bulk matrix signals indicated as red bars. Furthermore, a shoulder at the monomer band can be seen, possibly originating from the proton acceptors of various $\mathrm{BB}$ coordinating $\mathrm{N}$ or caused by the $\mathrm{N}$-coated monomer.

After reducing the $\mathrm{N}$ concentration to $2.5 \%$ two new signals at 3480 and $3474 \mathrm{~cm}^{-1}$ arise in addition to the established band positions of pure $\mathrm{B}$. Their downshift from $\mathrm{BB}$ indicates a $\mathrm{N}$ coordination of $\mathrm{BB}$ and therefore formation of $\mathrm{BBN}$ or $\mathrm{BBNN}$.

A further reduction of the $\mathrm{N}$ concentration to $1 \%$ results in a loss of intensity of the band at $3474 \mathrm{~cm}^{-1}$ relative to the band at $3480 \mathrm{~cm}^{-1}$. This indicates that the more strongly downshifted band is caused by a cluster containing more $\mathrm{N}$ than the band at $3480 \mathrm{~cm}^{-1}$. This supports the hypothesis that the double feature is caused by $\mathrm{BBN}$ and $\mathrm{BBNN}$, respectively. The qualitative behavior is thus similar to the $M$ case, but the peak separation for selectively and more globally solvated alcohol dimers is much smaller in B. We explain this in part with the bulky nature of $\mathrm{B}$, which does not allow for as much cooperativity between different solvation sites as $\mathrm{M}$. 
Table 4. Theoretically Predicted Harmonic $\left(\omega_{\mathrm{e}}\right) \mathrm{OH}$ Stretching Band Center Positions and Integrated Infrared Band Strengths $\left(S_{\omega}\right)$ of tert-Butyl Alcohol and tert-Butyl Alcohol-Nitrogen Complexes ${ }^{a}$ Obtained at the B3LYPD3(BJ)/aVTZ Level of Approximation

\begin{tabular}{|c|c|c|c|}
\hline structure & $\omega_{e} / \mathrm{cm}^{-1}$ & $S_{\omega} / \mathrm{km} \mathrm{mol}^{-1}$ & $\Delta \omega_{e} / \mathrm{cm}^{-1 b}$ \\
\hline B & 3801 & 14 & - \\
\hline $\mathrm{BN}_{\mathrm{H}}$ & 3810 & 87 & 9 \\
\hline $\mathrm{BN}_{\mathrm{O}}$ & 3801 & 14 & 0 \\
\hline $\mathrm{BN}_{\mathrm{C} 3}$ & 3801 & 15 & 0 \\
\hline $\mathrm{BN}_{\mathrm{C}}$ & 3801 & 14 & 0 \\
\hline $\mathrm{BN}_{\mathrm{H}} \mathrm{N}_{\mathrm{H}}$ & 3805 & 94 & 4 \\
\hline $\mathrm{N}_{\mathrm{O}} \mathrm{N}_{\mathrm{O}} \mathrm{B}$ & 3801 & 15 & 0 \\
\hline $\mathrm{N}_{\mathrm{O}} \mathrm{BN}_{\mathrm{H}}$ & 3810 & 92 & 9 \\
\hline $\mathrm{BN}_{\mathrm{H}} \mathrm{N}_{\mathrm{C} 3}$ & 3809 & 89 & 8 \\
\hline $\mathrm{N}_{\mathrm{O}} \mathrm{BN}_{\mathrm{C} 3}$ & 3801 & 15 & 0 \\
\hline$B \mathrm{~B}^{b}$ & 3795 & 19 & - \\
\hline$B B N_{H}$ & 3792 & 57 & -3 \\
\hline $\mathrm{N}_{\mathrm{O}} B \mathrm{~B}$ & 3795 & 20 & 0 \\
\hline$B \mathrm{BN}_{\mathrm{O}}$ & 3795 & 20 & 0 \\
\hline $\mathrm{N}_{\mathrm{O}} B \mathrm{BN} \mathrm{N}_{\mathrm{H}}$ & 3792 & 55 & -3 \\
\hline$B B N_{\mathrm{H}} \mathrm{N}_{\mathrm{H}}$ & 3792 & 128 & -3 \\
\hline$B B N_{\mathrm{H}} \mathrm{N}_{\mathrm{O}}$ & 3791 & 63 & -4 \\
\hline $\mathrm{N}_{\mathrm{O}} B \mathrm{BN} \mathrm{N}_{\mathrm{O}}$ & 3795 & 20 & 0 \\
\hline $\mathrm{B} B$ & 3614 & 525 & - \\
\hline $\mathrm{BBN}_{\mathrm{H}}$ & 3593 & 543 & -21 \\
\hline $\mathrm{N}_{\mathrm{O}} \mathrm{BB}$ & 3611 & 513 & -3 \\
\hline${\mathrm{B} B \mathrm{~N}_{\mathrm{O}}}$ & 3617 & 521 & 3 \\
\hline $\mathrm{N}_{\mathrm{O}} B B \mathrm{~N}_{\mathrm{H}}$ & 3590 & 530 & -24 \\
\hline $\mathrm{BBN} \mathrm{N}_{\mathrm{H}} \mathrm{N}_{\mathrm{H}}$ & 3586 & 571 & -28 \\
\hline $\mathrm{BBN} \mathrm{N}_{\mathrm{H}} \mathrm{N}_{\mathrm{O}}$ & 3596 & 533 & -18 \\
\hline $\mathrm{N}_{\mathrm{O}} \mathrm{BB} N_{\mathrm{O}}$ & 3614 & 512 & 0 \\
\hline
\end{tabular}

${ }^{a}$ Roman B symbols denote the tert-butyl alcohol monomer unit involved in the vibration; italic symbols, the passive monomer. ${ }^{b}$ Spectral harmonic shifts relative to the corresponding vibration in the pure tert-butyl alcohol fragments.
Ethanol-Nitrogen Complexes. Since the E monomer comes in two conformations (the slightly more stable $t$ at 3678 $\mathrm{cm}^{-1}$ and the chiral $g$ form at $\left.3660 \mathrm{~cm}^{-1}\right),{ }^{10,25}$ its dimers exhibit a larger conformational variety than $\mathrm{M}$ and $\mathrm{B}$. Among the possible EE conformations, six are predicted to be reasonably stable $^{47}$ and four were found in vibrational spectra, ${ }^{30}$ some of them with straightforward assignment. ${ }^{25}$ In a $\mathrm{N}$ matrix, the systematic interconversion of these conformations is possible. ${ }^{18}$ We note that the microwave structure assignment has recently been extended to the six most stable conformations of ethanol dimer, $^{48}$ going far beyond the capabilities of vibrational spectroscopy.

Spectra of E expanded in helium and more effectively cooled supersonic expansions by means of argon admixture are shown in Figure 5. The $60 \mathrm{~cm}$ absorption path of the filet-jet setup offers new insights into the well-known spectra of E clusters. A small band at $3572 \mathrm{~cm}^{-1}$ might be caused by coexcitation of the dimer donor $\mathrm{OH}$ stretching and a low-frequency mode, similar to the methanol trimer case. ${ }^{33}$ Argon-induced depopulation (lower trace in Figure 5) of the metastable dimer conformations with their donor bands at 3547 and 3539 $\mathrm{cm}^{-1}$ leads to an intensity loss of this band. Therefore, it can be associated with one of these depleted dimer conformations. The spectral separation corresponds to 25 and $33 \mathrm{~cm}^{-1}$. This may be compared to a bending mode of the two ethyl residues theoretically predicted around $30 \mathrm{~cm}^{-1}$ which slightly changes the hydrogen bond angle. The alternative assignment of the weak band to the $\mathrm{OH}$ stretching fundamental of another metastable dimer conformation is less likely according to calculations, because matching structures are very unstable with respect to conformational relaxation. The most stable $\mathrm{E}_{g+} \mathrm{E}_{g+}$ dimer with the donor band at $3531 \mathrm{~cm}^{-1}$ gains intensity relative to all other conformations upon argon addition and its acceptor $\mathrm{OH}$ stretching fundamental previously known from Raman spectroscopy $^{25}$ appears at $3653 \mathrm{~cm}^{-1}$.

The broad trimer band displays four discernible shoulders at $3462,3454,3446$, and $3440 \mathrm{~cm}^{-1}$. The $3446 \mathrm{~cm}^{-1}$ band gains

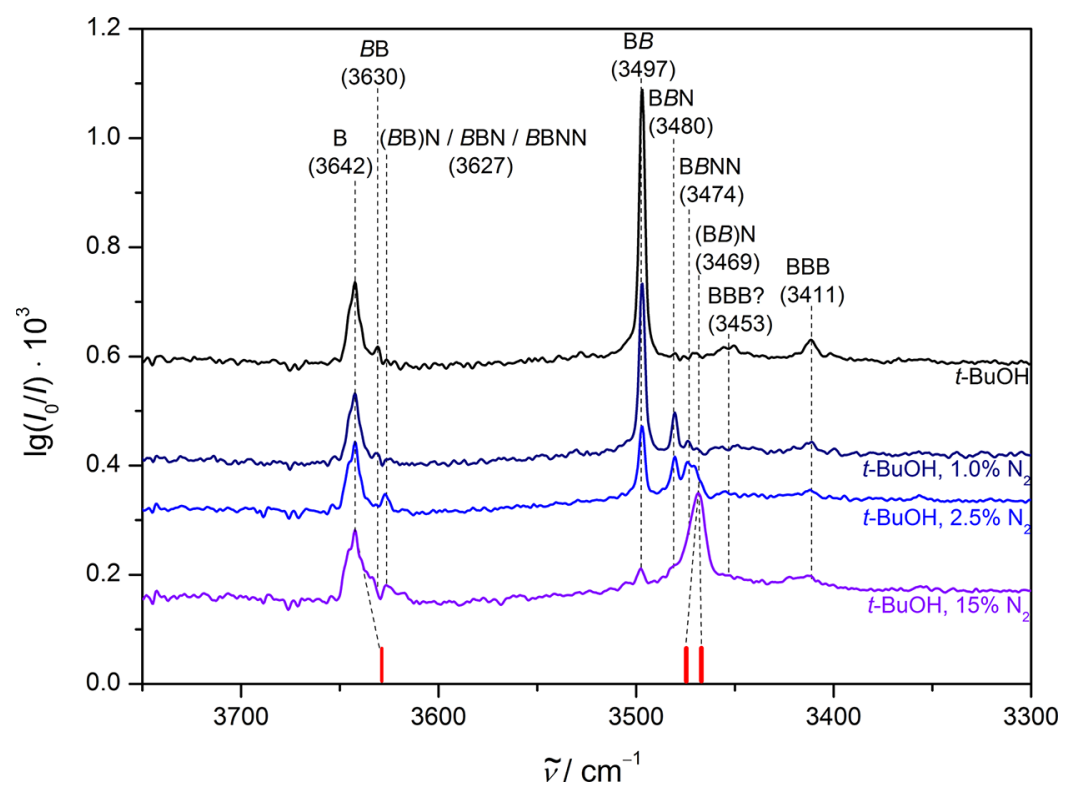

Figure 4. FTIR jet spectra of tert-butyl alcohol expanded in helium (black trace), 1.0\% nitrogen in helium (dark blue trace), $2.5 \%$ nitrogen in helium (blue trace) and $15 \%$ nitrogen in helium (violet trace). Red bars at the bottom indicate the most dominant signals in a nitrogen matrix taken from ref 23. Labels and wavenumbers for (tentative) assignments are provided. 


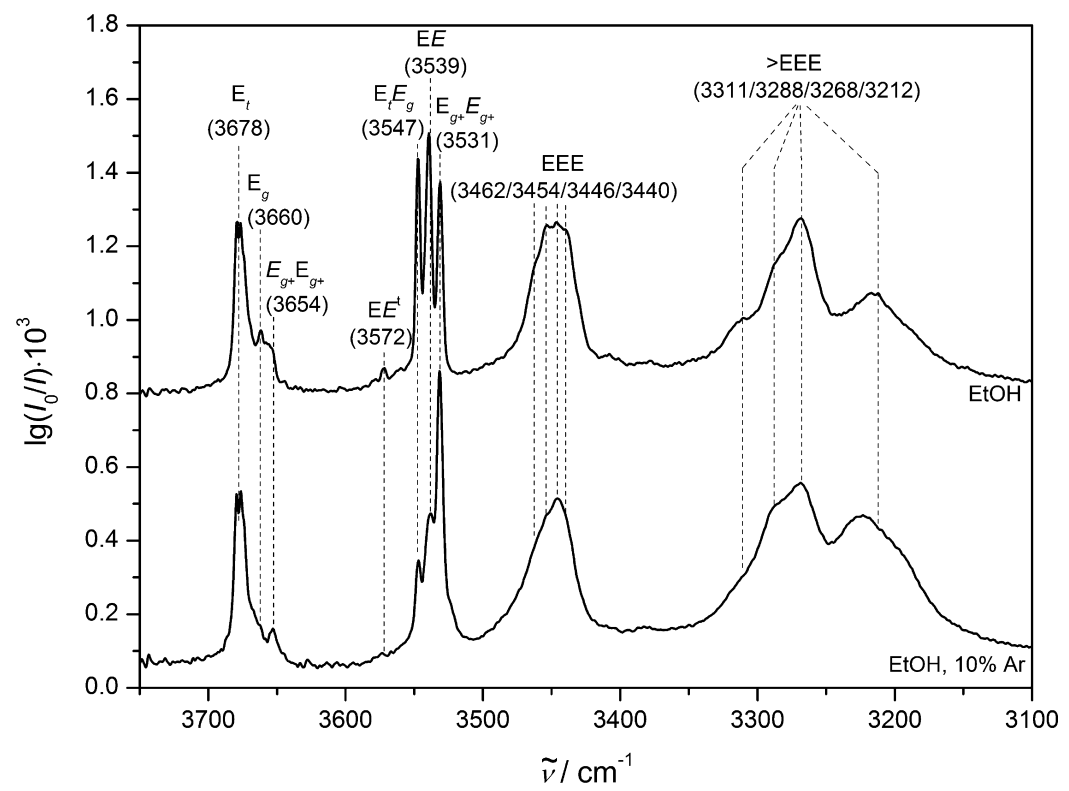

Figure 5. FTIR jet spectra of ethanol expanded in helium (upper trace) and 10\% Ar in helium (lower trace), showing the depletion of a lowfrequency combination band $\mathrm{E}^{t}$ together with its parent $\mathrm{OH}$ stretching band upon $\mathrm{Ar}$ admixture. Labels and wavenumbers for (tentative) assignments are provided.

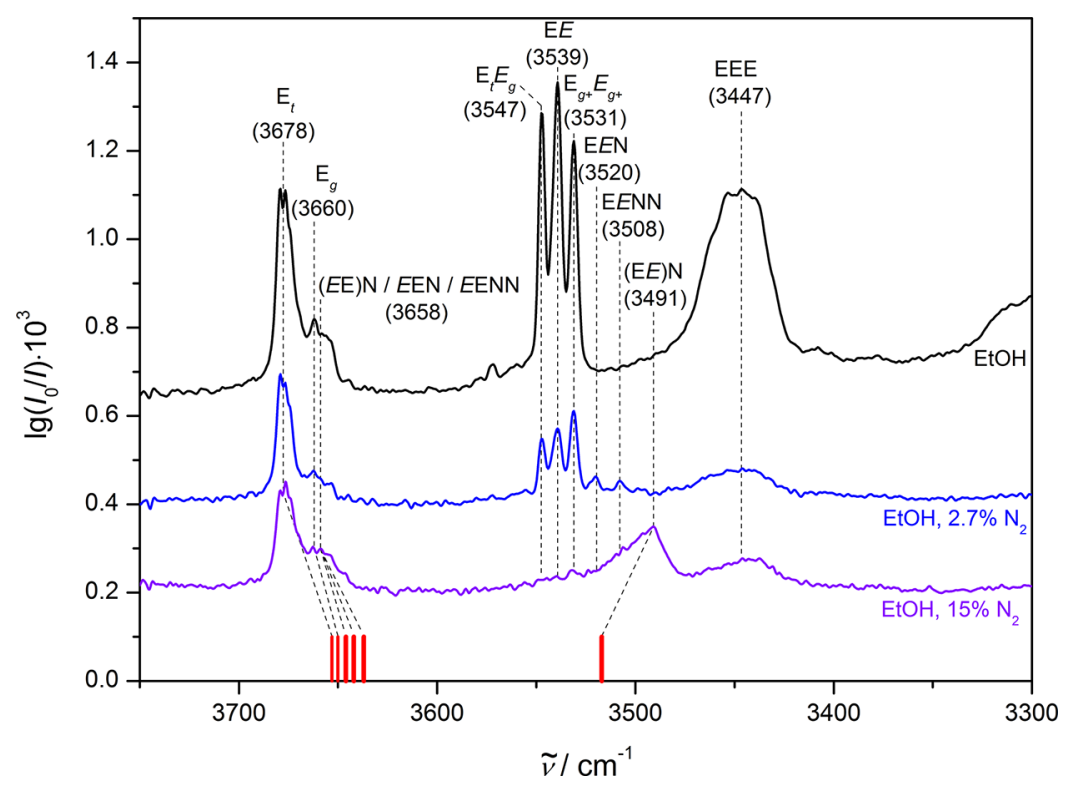

Figure 6. FTIR jet spectra of ethanol expanded in helium (black trace), 2.7\% nitrogen in helium (blue trace) and $15 \%$ nitrogen in helium (violet trace). Red bars at the bottom indicate the most dominant signals in a nitrogen matrix taken from refs 10 and 18 . According to ref $18, \mathrm{E}_{t} \mathrm{E}_{g}$ is the most stable conformation in the bulk matrix. Labels and wavenumbers for (tentative) assignments are provided.

intensity relative to the others upon improved cooling. In the spectral region of tetramers and larger clusters, shoulders at $3311,3288,3268$, and $3212 \mathrm{~cm}^{-1}$ are found, the latter is upshifted in an argon-containing expansion. This is the first time that conformational structure is revealed in EEE and EEEE spectra, but the homogeneous and residual inhomogeneous broadening is too large compared to the shift differences to allow for tentative assignments. Helium droplet experiments might achieve a better resolution, but at the price of a solvation shift and the possibilty of stabilizing metastable conformations.

FTIR jet spectra of various E-N mixtures are depicted in Figure 6. Similar to $M$ and $B$, two bands at 3520 and 3508 $\mathrm{cm}^{-1}$, downshifted from the homodimer donors, emerge with a $\mathrm{N}$ fraction of $2.7 \%$ in the expansion. The close analogy to the other alcohols suggests, that EEN and EENN are the cause for these spectral features but in this case conformational isomerism generates similar splittings. One interpretation is that conformational isomerism is removed by $\mathrm{N}$ addition. Alternatively, there could be fortuitous band overlap between different conformational and $\mathrm{N}$-coordinated species. Addition of $15 \% \mathrm{~N}$ again results in nanocoated dimers. Interestingly, the peak position at $3491 \mathrm{~cm}^{-1}$ is downshifted from the bulk matrix value $^{18}$ of $3517 \mathrm{~cm}^{-1}$, while $\mathrm{M}$ displayed a small upshift and B almost no shift from bulk matrix to nanocoating in our supersonic expansion. This is most likely due to the higher degree of conformational isomerism possible for E. Apparently, $\mathrm{N}$ coating in supersonic expansions generates different conformations than bulk matrix deposition. 
Quantum chemical calculations for mixed E-N clusters display the same binding sites for $\mathrm{N}$ already observed in $\mathrm{M}$ and $\mathrm{B}$. The mixed trimer most certainly prefers an $\mathrm{EEN}_{\mathrm{H}}$ conformation. The most stable conformation found in this study is $\mathrm{E}_{g-} \mathrm{E}_{g+} \mathrm{N}_{\mathrm{H}}$, although 11 similar structures featuring other EE conformers are predicted to be in a $1 \mathrm{~kJ} \mathrm{~mol}^{-1}$ energy window, well below the error of the employed theoretical approximation. Figure 7 shows the predicted incremental

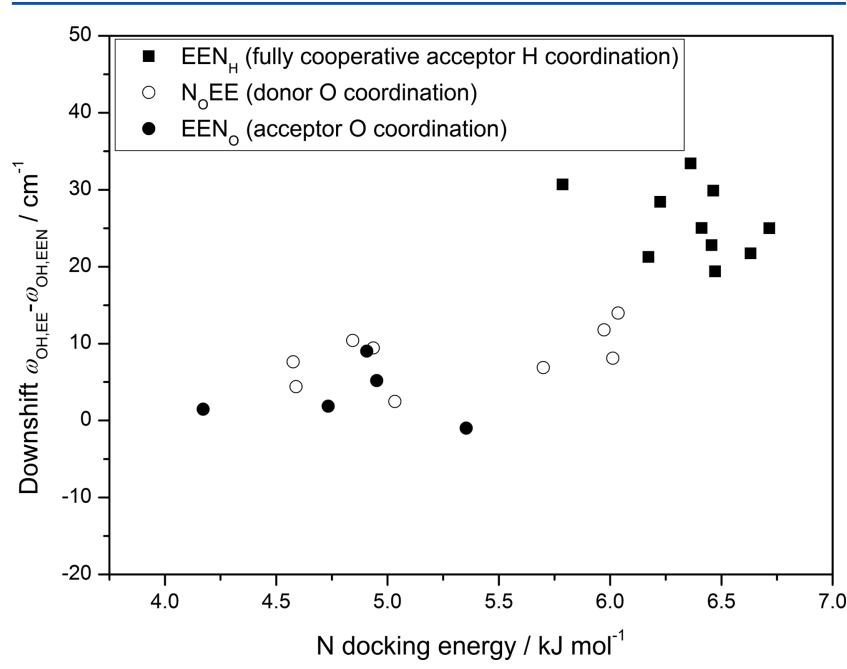

Figure 7. Predicted incremental spectral downshift of EEN from the corresponding EE structure calculated at the B3LYP-D3(BJ)/aVTZ level plotted against the zero-point corrected dissociation energy of EEN into the corresponding EE conformer and $\mathrm{N}$ (docking energy).

spectral shift for EEN from the corresponding EE structure plotted against the zero-point corrected dissociation energy of EEN into the corresponding EE conformer and N. There is an increasing docking energy and downshift effect of $\mathrm{N}$ from acceptor $\mathrm{O}$ coordination (where it competes with the $\mathrm{OH}$ donor) over donor $\mathrm{O}$ coordination (where it reinforces the $\mathrm{OH}$ donor) to a fully cooperative acceptor $\mathrm{H}$ coordination. However, the scatter among different EE conformations is too large to allow for an unambiguous separation of conformational and $\mathrm{N}$ coordination effects on the band position. The mixed tetramer displays an equally large conformational variety. The most stable $\mathrm{E}_{t} \mathrm{E}_{t} \mathrm{~N}_{\mathrm{H}} \mathrm{N}_{\mathrm{H}}$ structure is accompanied by nine conformers at most $1 \mathrm{~kJ} \mathrm{~mol}^{-1}$ less stable. Therefore, a safe assignment of the experimentally observed bands to a specific EEN or EENN conformation is currently not possible. However, a compelling hypothesis is that $\mathrm{N}$ coating of $\mathrm{EE}$ conserves the strongly shifting $\mathrm{E}_{g+} \mathrm{E}_{g+}$ conformation, whereas a bulk matrix may induce $\mathrm{E}_{t}$ donor conformations in the embedded dimer. ${ }^{18}$ This would explain the unusually small matrix isolation shift for EE, which was also found for argon. ${ }^{30}$ As will be elaborated below, it requires assignment of the two observed mixed complex bands to two different EEN conformations.

Alkylation Trends. Table 5 summarizes the experimental band positions of $\mathrm{N}$ complexes found in this work together with previously known band positions of the corresponding $\mathrm{N}$ free species. These data allow for a discussion of alkylation trends in the $\mathrm{N}$ coordination. Table 6 compares the resulting shifts among the different alcohols. The first line of each block represents the alcohol dimerization shift (with respect to the donor conformation). Experimentally, it grows significantly from $\mathrm{M}$ over $\mathrm{E}_{g}$ to $\mathrm{B}$, whereas the harmonic predictions are
Table 5. Experimental OH Stretching Band Centers of Monomers and Clusters

\begin{tabular}{lr}
\multicolumn{1}{c}{ structures } & $\tilde{\nu} / \mathrm{cm}^{-1}$ \\
$\mathrm{M}$ & 3685 \\
$M \mathrm{M}$ & $3684^{26} / 3675^{27}$ \\
$(M \mathrm{M}) \mathrm{N} / M M N / M M N N$ & 3663 \\
$\mathrm{MM}$ & 3575 \\
$\mathrm{MMN}$ & 3543 \\
$\mathrm{MMNN}$ & 3534 \\
$(\mathrm{MM}) \mathrm{N}$ & 3512 \\
$\mathrm{~B}$ & 3642 \\
$B \mathrm{~B}$ & 3630 \\
$(B \mathrm{~B}) \mathrm{N} / B \mathrm{BN} / B \mathrm{BNN}$ & 3627 \\
$\mathrm{BB}$ & 3497 \\
$\mathrm{BBN}$ & 3480 \\
$\mathrm{BBNN}$ & 3474 \\
$(\mathrm{BB}) \mathrm{N}$ & 3469 \\
$\mathrm{E}_{t}$ & 3678 \\
$\mathrm{E}_{g}$ & 3660 \\
$E_{g+} \mathrm{E}_{g+}$ & 3654 \\
$(E \mathrm{E}) \mathrm{N} / \mathrm{EEN} / E \mathrm{ENN}$ & 3658 \\
$\mathrm{E}_{g+} E_{g+}$ & 3531 \\
$\mathrm{E} E \mathrm{~N}$ & 3520 \\
$\mathrm{E} E \mathrm{NN}$ & 3508 \\
$(\mathrm{EE}) \mathrm{N}$ & 3491 \\
\end{tabular}

Table 6. Experimental $\left(\Delta \tilde{\nu}_{\text {exp }}\right)$ and Harmonic $\left(\Delta \omega_{\text {theo }}\right)$ and anharmonic $\left(\Delta \tilde{\nu}_{\text {theo }}\right)^{a} \mathrm{OH}$ Stretching Shift Predicted at the B3LYP-D3(BJ)/aVTZ Level between the Structures Given in the First Column

\begin{tabular}{lrrr}
\multicolumn{1}{c}{ structures } & $\Delta \tilde{\nu}_{\text {exp }} / \mathrm{cm}^{-1}$ & $\Delta \omega_{\text {theo }} / \mathrm{cm}^{-1}$ & $\Delta \tilde{\nu}_{\text {theo }} / \mathrm{cm}^{-1}$ \\
$M M-M$ & -110 & -176 & -171 \\
$M M N-M M$ & -32 & -24 & -44 \\
$M M N N-M M$ & -41 & -35 & $274 /-79 /-114^{b}$ \\
$(\mathrm{MM}) \mathrm{N}-\mathrm{MM}$ & -63 & - & - \\
$\mathrm{B} B-\mathrm{B}$ & -145 & -188 & - \\
$\mathrm{B} B N-\mathrm{B} B$ & -17 & -21 & - \\
$\mathrm{B} B N N-\mathrm{BB}$ & -23 & -24 & - \\
$(\mathrm{B} B) \mathrm{N}-\mathrm{BB}$ & -28 & - & - \\
$\mathrm{E}_{g+} E_{g+}-\mathrm{E}_{g}$ & -129 & -176 & - \\
$\mathrm{E} E \mathrm{~N}-\mathrm{E}_{g+} E_{g+}$ & -11 & -28 & - \\
$\mathrm{E} E N N-\mathrm{E}_{g+} E_{g+}$ & -23 & -33 & - \\
$(\mathrm{E} E) \mathrm{N}-\mathrm{E}_{g+} E_{g+}$ & -40 & - & -
\end{tabular}

${ }^{a}$ VPT2, Gaussian 09 E.01. ${ }^{b}$ The VPT2 predictions, which are usually reasonably robust for high frequency modes, show large numerical noise in this case despite very tight optimization criteria.

more or less constant and much larger. The latter is an artifact of the B3LYP level, ${ }^{45}$ whereas the former will be discussed below.

The additional shift induced by the first $\mathrm{N}$ is largest for $\mathrm{M}$ (see below), intermediate for B and smallest for $\mathrm{E}$. The latter may hint at a conformational change, which we cannot resolve in the present work. This would require a microwave study in analogy to that of $\mathrm{EE}^{48,49}$ and the $\mathrm{E}$ argon complex. ${ }^{50}$ The harmonically predicted shift is smaller for $\mathrm{M}$, similar for B and larger for E, supporting a conformational change in EEN. Anharmonic predictions are in part unstable and shall therefore not be discussed further. The experimental shift caused by two coordinating $\mathrm{N}$ units follows a similar, but attenuated alkylation trend. The agreement with the harmonic prediction is better, 
but again worst for E. Finally, the experimental nanocoating shift (last row in each block of Table 6) can be discussed. It is very large for $\mathrm{M}$, small for $\mathrm{B}$ and intermediate for $\mathrm{E}$, just opposite to the alcohol dimerization shift trend. We will come back to this later on.

Figure 8 further illustrates the experimental $\mathrm{N}$ nanocoating trends for the three alcohols. The $\mathrm{BB}$ case is straightforward to

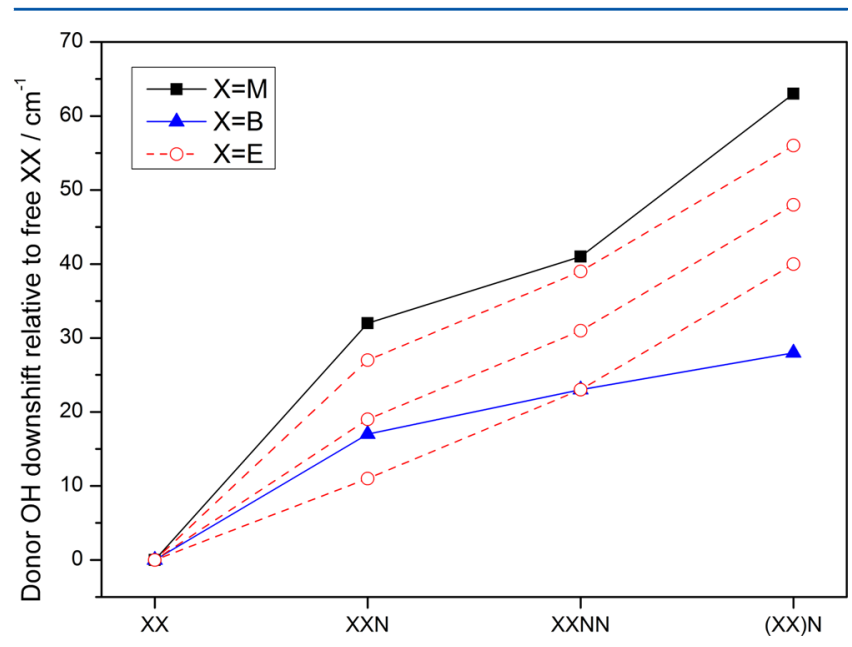

Figure 8. Experimental $\mathrm{OH}$ stretching downshift trends as a function of $\mathrm{N}$ decoration of alcohol dimers, quickly saturating for the bulky $\mathrm{B}$, but not for M. For the intermediate alcohol E, the three dashed trends correspond to different uniform conformational $\mathrm{EE}$ assignments. Assignment to $\mathrm{E}_{g+} \mathrm{E}_{g+}$ (lowest trend) upon $\mathrm{N}$ docking is seen to be inconsistent with $\mathrm{B}$ and $\mathrm{M}$.

understand, with a quickly saturating $\mathrm{OH}$ donor downshift due to limited access of $\mathrm{N}$ to the bulky alcohol dimer. $\mathrm{MM}$ offers more access to the matrix host and even the step from two to more $\mathrm{N}$ units is substantial, possibly due to large amplitude quenching, as we will elaborate below. The case of EE should be intermediate, but it all depends on conformational assignment. The dashed lines arbitrarily assume uniform assignment along the nanocoating coordinate. The lowest one assumes $\mathrm{E}_{g_{+}} \mathrm{E}_{g_{+}}$and is unlikely because of the low XXN data point. The highest one is unlikely because it does not fit the bulk matrix finding, ${ }^{18}$ which was discussed above. The intermediate one may also be incorrect, because it could be that the two observed bands are due to two different XXN complexes rather than to XXN and XXNN. Microwave spectroscopy may be needed to further elucidate this.

Table 7 summarizes the calculated energetics behind these spectral trends, with and without zero-point energy. For $\mathrm{M}$ and $\mathrm{E}$, single point $\operatorname{CCSD}(\mathrm{T})$ refinements were also carried out. The dissociation energy of $\mathrm{N}$ from an alcohol monomer is similar for all three cases, namely about $6-7 \mathrm{~kJ} \mathrm{~mol}^{-1}$ before and $4-5 \mathrm{~kJ} \mathrm{~mol}^{-1}$ after zero-point energy correction. Adding to their lower IR visibility and smaller spectral shifts, this further explains why the corresponding binary complexes are difficult to observe in the jet in competition with the cooperative complexes. It also shows that the interaction is largely electrostatic, because polarization and dispersion effects should increase strongly with growing size of the alkyl group. Dissociation of $\mathrm{N}$ from an alcohol dimer is significantly more difficult, ranging from 9 to $11 \mathrm{~kJ} \mathrm{~mol}^{-1}$ without and from 6 to 8 $\mathrm{kJ} \mathrm{mol}^{-1}$ with zero-point energy correction. The increase from $\mathrm{M}$ to $\mathrm{B}$ is more pronounced, cooperative polarization clearly more important. The second $\mathrm{N}$ is attached somewhat less strongly for the bulky B case. This certainly contributes to the faster saturation of the solvation shift for B dimers. The E case remains difficult to judge because of the unknown conformation.

It is rewarding to compare the experimental difference between monomer and dimer donor $\mathrm{OH}$ wavenumbers more closely for the clear-cut cases of $\mathrm{M}$ and $\mathrm{B}$, where conformational isomerism does not complicate the picture. The quantity $\Delta_{\mathrm{B}-\mathrm{M}}=\tilde{\nu}_{\mathrm{B}}$ (monomer $)-\tilde{\nu}_{\mathrm{B}}($ dimer donor $)-\left(\tilde{\nu}_{\mathrm{M}}\right.$ (monomer $)$ - $\tilde{\nu}_{M}($ dimer donor $\left.)\right)$ is plotted in Figure 9 as a function of progressive $\mathrm{N}$ coordination. For the free alcohols and their dimers, it amounts to $35 \mathrm{~cm}^{-1}$, with the larger dimerization shift for B. For the alcohol dimer signals attributed to single, double and multiple $\mathrm{N}$ coordination in this work, we assume that the corresponding (unobserved) monomer band position is more or less unshifted or at least similarly shifted by $\mathrm{N}$-coordination for $B$ and $M$. This introduces an error bar of about $\pm 5 \mathrm{~cm}^{-1}$. For the bulk matrix, the site effects in $\mathrm{BB}$ introduce a similar error bar and we approximate the site effects in MM by assuming a total error bar of $\pm 15 \mathrm{~cm}^{-1}$. Figure 9 shows that $\Delta_{\mathrm{B}-\mathrm{M}}$ drops steadily to a value close to zero when the dimers are $\mathrm{N}$-coated. If one assumes that large amplitude motion in the hydrogen bonded alcohol dimers is reduced by $\mathrm{N}$ coating and also by increasing the mass of the alcohol, this suggests that the intrinsic downshifts of $\mathrm{M}$ and $\mathrm{B}$ dimers may be quite similar, if such large amplitude effects are removed. Indeed, harmonic

Table 7. Incremental Electronic $\left(D_{\mathrm{e}}\right)$ and Harmonic Vibrational Zero-Point Corrected $\left(D_{0}\right)$ Dissociation Energies of the Different Alcohol-Nitrogen Heteroaggregates into the Corresponding Homoaggregates and Isolated $\mathbf{N}$

\begin{tabular}{|c|c|c|c|c|}
\hline \multirow[b]{2}{*}{ structures } & \multicolumn{2}{|c|}{ B3LYP-D3(BJ)/aVTZ } & \multicolumn{2}{|c|}{$\operatorname{CCSD}(\mathrm{T}) / \mathrm{aVTZ}$} \\
\hline & $D_{\mathrm{e}} / \mathrm{kJ} \mathrm{mol}^{-1}$ & $D_{0} / \mathrm{kJ} \mathrm{mol}^{-1}$ & $D_{\mathrm{e}} / \mathrm{kJ} \mathrm{mol}^{-1}$ & $D_{0} / \mathrm{kJ} \mathrm{mol}^{-1 a}$ \\
\hline $\mathrm{MN}_{\mathrm{H}} \rightarrow \mathrm{M}+\mathrm{N}$ & 6.0 & 3.5 & 6.9 & 4.5 \\
\hline $\mathrm{MMN}_{\mathrm{H}} \rightarrow \mathrm{MM}+\mathrm{N}$ & 8.8 & 6.0 & 10.1 & 7.3 \\
\hline $\mathrm{MMN}_{\mathrm{H}} \mathrm{N}_{\mathrm{H}} \rightarrow \mathrm{MMN}_{\mathrm{H}}+\mathrm{N}$ & 8.1 & 6.1 & 10.3 & 8.4 \\
\hline $\mathrm{BN}_{\mathrm{H}} \rightarrow \mathrm{B}+\mathrm{N}$ & 6.3 & 4.2 & - & - \\
\hline $\mathrm{BBN}_{\mathrm{H}} \rightarrow \mathrm{BB}+\mathrm{N}$ & 10.2 & 7.8 & - & - \\
\hline $\mathrm{N}_{\mathrm{O}} \mathrm{BBN}_{\mathrm{H}} \rightarrow \mathrm{BBN}_{\mathrm{H}}+\mathrm{N}$ & 7.6 & 6.1 & - & - \\
\hline $\mathrm{BBN}_{\mathrm{H}} \mathrm{N}_{\mathrm{H}} \rightarrow \mathrm{BBN}_{\mathrm{H}}+\mathrm{N}$ & 7.2 & 5.5 & - & - \\
\hline $\mathrm{E}_{t} \mathrm{~N}_{\mathrm{H}} \rightarrow \mathrm{E}_{t}+\mathrm{N}$ & 5.9 & 3.7 & 7.1 & 4.8 \\
\hline $\mathrm{E}_{g-} \mathrm{E}_{g+} \mathrm{N}_{\mathrm{H}} \rightarrow \mathrm{E}_{g-} \mathrm{E}_{g^{+}}+\mathrm{N}$ & 9.4 & 6.7 & 11.3 & 8.6 \\
\hline $\mathrm{E}_{t} \mathrm{E}_{t} \mathrm{~N}_{\mathrm{H}} \mathrm{N}_{\mathrm{H}} \rightarrow \stackrel{0}{\mathrm{E}_{t}} \mathrm{E}_{t} \mathrm{~N}_{\mathrm{H}}+\mathrm{N}$ & 8.4 & 6.9 & - & - \\
\hline
\end{tabular}

${ }^{a}$ Harmonic zero-point vibrational energy was taken from the B3LYP-D3(BJ)/aVTZ results. 


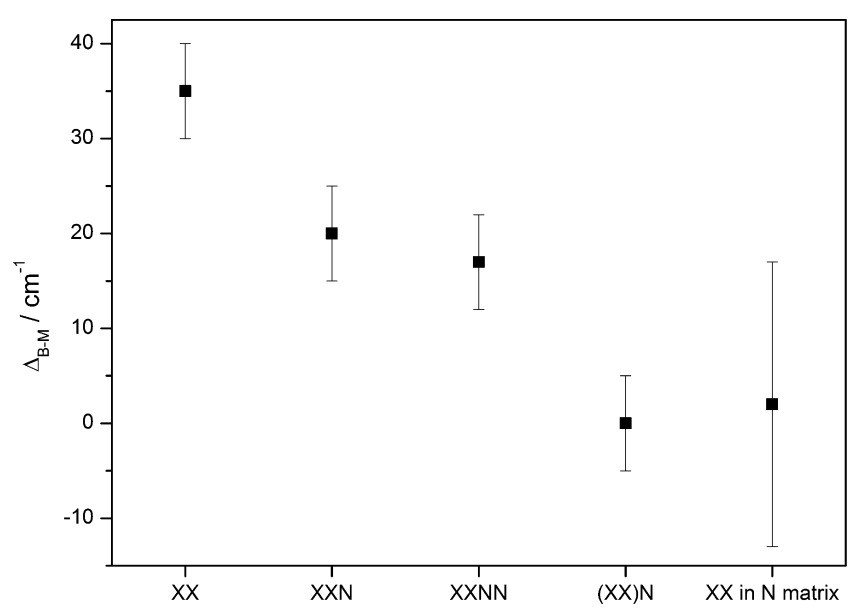

Figure 9. Experimental difference between $\mathrm{B}$ and $\mathrm{M}$ donor $\mathrm{OH}$ stretching downshifts from monomer to dimer $\Delta_{\mathrm{B}-\mathrm{M}}$ as a function of progressive $\mathrm{N}$ coordination of $\mathrm{XX}(\mathrm{X}=\mathrm{M}, \mathrm{B})$.

downshifts of $\mathrm{M}$ and $\mathrm{B}$ dimers are predicted quite similarly (Table 6 and ref 51) and the picture does not change significantly when experimental diagonal anharmonicities ${ }^{6}$ are added. Furthermore, the best predicted downshifts after diagonal anharmonicity correction are closer to the downshifts observed in $\mathrm{N}$ matrices than to vacuum-isolated values. All this suggests that alcohols and their dimers embedded in $\mathrm{N}$ matrices show more comparable off-diagonal anharmonicity effects than the free systems. From such a coarse-grained perspective, the unusually small $\mathrm{OH}$ stretching downshift of isolated $\mathrm{MM}$ is an outlier due to large amplitude motion which weakens the hydrogen bond. This reduces the downshift, but the effect apparently becomes successively quenched by $\mathrm{N}$-coating and this contributes to the large MM matrix shift from 3575 to 3504 $\mathrm{cm}^{-1}$. B is more regular, because there is less large amplitude motion to quench, and therefore, the matrix shift of $\mathrm{BB}$ is three times smaller. It does not vanish because of the universal cooperative strengthening of $\mathrm{OH} \cdots \mathrm{OH} \cdots \mathrm{N}_{2}$ interactions relative to $\mathrm{OH} \cdots \mathrm{N}_{2}$ interactions, which was discussed above. Some support for this interpretation comes from a comparison of argon matrix data for $\mathrm{M}$ and $\mathrm{B}^{4,23}$ summarized in Table $\mathrm{S} 2$ in the Supporting Information. As in the case of nitrogen matrices, the dimerization downshift is equal within error bars due to site splittings $\left((135 \pm 15) \mathrm{cm}^{-1}\right.$ for B and $(140 \pm 12) \mathrm{cm}^{-1}$ for $\left.\mathrm{M}\right)$. The shifts are less pronounced due to less cooperative host interaction for the nonquadrupolar argon host, but the quenching still appears to be in place. It would be interesting to carry on the comparison to the more weakly interacting neon host, ${ }^{6}$ where the $\mathrm{M}$ dimerization downshift decreases to $(125 \pm 4) \mathrm{cm}^{-1}$, thus getting significantly closer to the jet value. Assuming that quenching of large amplitude anharmonic motion is less efficient in neon, the B dimerization downshift should now start to diverge from the $M$ value, but we are not aware of an experimental value.

At this stage, it can be rewarding to switch the perspective and to look at the effect of alcohol coordination on the $\mathrm{N}$ stretching wavenumber and IR band strength. Table 8 summarizes the most prominent effects. The upshift and IR activation of this normal mode due to alcohol coordination increases with hydrogen bond cooperativity, but only moderately. As expected, the $\mathrm{OH}$ stretching fundamental is a more sensitive probe of the interaction.
Table 8. Theoretically Predicted Harmonic $\left(\omega_{\mathrm{e}}\right) \mathrm{NN}$ Stretching Band Center Positions, Integrated Infrared Band Strengths $\left(S_{\omega}\right)$ and Spectral Shifts $\left(\Delta \omega_{\mathrm{e}}\right)$ from the Structures Given in the First Column to Isolated Nitrogen $(\mathrm{N})$ Obtained at the B3LYP-D3(BJ)/aVTZ Level of Approximation

\begin{tabular}{lccc} 
structure & $\omega_{\mathrm{e}} / \mathrm{cm}^{-1}$ & $S_{\omega} / \mathrm{km} \mathrm{mol}^{-1}$ & $\Delta \omega_{\mathrm{e}} / \mathrm{cm}^{-1}$ \\
$\mathrm{~N}$ & 2447 & 0.0 & - \\
$\mathrm{MN}_{\mathrm{H}}$ & 2453 & 0.4 & 6 \\
$\mathrm{BN}_{\mathrm{H}}$ & 2453 & 0.3 & 6 \\
$\mathrm{E}_{t} \mathrm{~N}_{\mathrm{H}}$ & 2453 & 0.3 & 6 \\
$\mathrm{MMN}_{\mathrm{H}}$ & 2456 & 0.8 & 9 \\
$\mathrm{BBN}_{\mathrm{H}}$ & 2455 & 0.5 & 8 \\
$\mathrm{E}_{g-} \mathrm{E}_{g_{+}} \mathrm{N}_{\mathrm{H}}$ & 2455 & 0.5 & 8 \\
\hline
\end{tabular}

\section{CONCLUSIONS}

A key result of the present study is the activating effect of an additional alcoholic donor on the $\mathrm{OH} \cdots \mathrm{N}_{2}$ interaction, also detected as an activating effect of nitrogen on the $\mathrm{OH} \cdots \mathrm{OH}$ interaction (Figure 10). This is typical for cooperative effects-

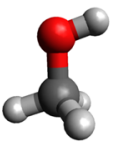

(a)

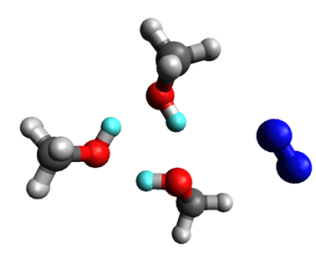

(d)

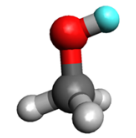

(b)

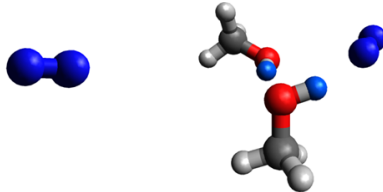

(c)

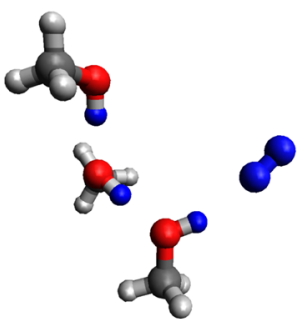

(e)

Figure 10. $\mathrm{OH}$ group of methanol (a) is polarized by nitrogen coordination (symbolized by increasing shades of blue on the $\mathrm{H}$ atom) and the $\mathrm{OH}$ bond weakened somewhat. A second hydrogen-bonded $\mathrm{OH}$ group acts as an amplifier of the weakening effect of nitrogen on $\mathrm{OH}$ bonds and at the same time as a frequency shifter to prevent spectral overlap. In the mixed dimer (b), the spectral effect is small, in the mixed trimer $(c)$ it is substantial and even sensitive to secondary nitrogen coordination. In cyclic alcohol trimers (d), there is no attractive docking site left for nitrogen. Nitrogen decoration could thus be a sensitive probe (or even promoter) for trimeric chain aggregation (e) of (bulky) alcohols.

they show up in all three binding partners, although the effect on the nitrogen vibration remains to be detected experimentally in these systems. While such effects are orders of magnitude weaker than practically relevant acid-catalyzed dinitrogen activation steps, ${ }^{52}$ they may be of interest for the characterization of prereactive nitrogen complexes. Similar to two metal centers which can enhance the activation of nitrogen over a single one, ${ }^{53}$ two $\mathrm{OH}$ groups enhance the action of a single one. Isolated $\mathrm{OH} \cdots \mathrm{N}_{2}$ hydrogen bonds show little IR activity and spectral overlap with the isolated $\mathrm{OH}$ stretching fundamental. Coordination of the oxygen by another $\mathrm{OH}$ group leads to cooperative polarization and significant shifts of 
the donor $\mathrm{OH}$ group. A second nitrogen binding partner, either to the donor oxygen or more likely sharing the acceptor hydrogen with the first, further enhances the downshift of the donor $\mathrm{OH}$ group. Further nitrogen decoration leads to converging infrared absorption bands which are in reasonable agreement with bulk nitrogen matrix spectra. Ethanol forms a prominent exception, indicative of different conformational preferences in nano vs bulk matrices. Alcohol trimer bands do not show such a pronounced spectral evolution with nitrogen decoration, due to their cyclic nature. In the future, one could even consider using nitrogen as a detector for chain aggregates with dangling $\mathrm{OH}$ groups, similar to its use in ice particles. ${ }^{54}$ Furthermore, it will be of interest to study the effects of such interactions on the dinitrogen vibration, either through IRactivation of this vibration ${ }^{55}$ or using Raman detection. Equally important would be structural verifications of these mixed complexes by broadband microwave spectroscopy. ${ }^{48}$

The experimental results in this work help in rationalizing the anomalously small dimerization shift of the methanol $\mathrm{OH}$ stretching fundamental in the gas phase. After having established its harmonic value at high computational level ${ }^{45}$ and its diagonal anharmonicity from overtone jet experiments, ${ }^{6}$ important off-diagonal contributions had been worked out with the help of matrix isolation spectroscopy, ${ }^{46,56}$ but others-in particular the acceptor torsion coupling-had to remain open. By adding nitrogen binding partners to the acceptor $\mathrm{OH}$ up to the bulk limit, the methanol dimer was shown in the present work to systematically approach the more bulky tert-butyl alcohol dimer in terms of dimerization shift. What remains is a high level comparison of harmonic dimerization shifts of methanol and tert-butyl alcohol to check whether this similarity is more than coincidental. If these high level harmonic shifts turn out to be similar, nitrogen embedding of alcohol dimers somehow cancels any differences in off-diagonal anharmonicity contributions to the $\mathrm{OH}$ fundamental wavenumber between light and heavy alcohols.

\section{ASSOCIATED CONTENT}

\section{S Supporting Information}

The Supporting Information is available free of charge on the ACS Publications website at DOI: 10.1021/acs.jpca.7b01265.

Matrix shift compilation, Gaussian09 version variation, local minimum structures and energies, and Cartesian coordinates for selected cluster structures (PDF)

\section{AUTHOR INFORMATION}

\section{Corresponding Author}

*(M.A.S.) E-mail: msuhm@gwdg.de. Telephone: +49 551 3933112. Fax: +49 $55139-33117$.

\section{ORCID}

Martin A. Suhm: 0000-0001-8841-7705

Notes

The authors declare no competing financial interest.

\section{ACKNOWLEDGMENTS}

Support from the DFG (SU 121/4) is gratefully acknowledged. S.O. thanks the FCI for a generous scholarship. We thank Stephane Coussan and the anonymous reviewers for very helpful remarks.

\section{REFERENCES}

(1) Whittle, E.; Dows, D. A.; Pimentel, G. C. Matrix Isolation Method for the Experimental Study of Unstable Species. J. Chem. Phys. 1954, 22, 1943-1944.

(2) van Thiel, M.; Becker, E. D.; Pimentel, G. C. Infrared Studies of Hydrogen Bonding of Methanol by the Matrix Isolation Technique. J. Chem. Phys. 1957, 27, 95-99.

(3) Nelander, B. The Peroxy Radical as Hydrogen Bond Donor and Hydrogen Bond Acceptor. A Matrix Isolation Study. J. Phys. Chem. A 1997, 101, 9092-9096.

(4) Perchard, J. P.; Mielke, Z. Anharmonicity and Hydrogen Bonding: I. A Near-infrared Study of Methanol Trapped in Nitrogen and Argon Matrices. Chem. Phys. 2001, 264, 221-234.

(5) Yoshioka, K.; Raston, P. L.; Anderson, D. T. Infrared Spectroscopy of Chemically Doped Solid Parahydrogen. Int. Rev. Phys. Chem. 2006, 25, 469-496.

(6) Kollipost, F.; Papendorf, K.; Lee, Y.-F.; Lee, Y.-P.; Suhm, M. A. Alcohol Dimers - How Much Diagonal OH Anharmonicity? Phys. Chem. Chem. Phys. 2014, 16, 15948-15956.

(7) Andersen, J.; Heimdal, J.; Mahler, D. W.; Nelander, B.; Larsen, R. W. Communication: $\mathrm{THz}$ Absorption Spectrum of the $\mathrm{CO}_{2}-\mathrm{H}_{2} \mathrm{O}$ Complex: Observation and Assignment of Intermolecular van der Waals Vibrations. J. Chem. Phys. 2014, 140, 091103.

(8) Toennies, J. P.; Vilesov, A. F. Superfluid Helium Droplets: A Uniquely Cold Nanomatrix for Molecules and Molecular Complexes. Angew. Chem., Int. Ed. 2004, 43, 2622-2648.

(9) Crépin, C.; Tramer, A. Rare-gas Matrix as an Infinite Rare-gas Cluster: A Spectroscopic Study of 9,10-dichloroanthracene in Argon Matrices. Chem. Phys. Lett. 1990, 170, 446-450.

(10) Coussan, S.; Bouteiller, Y.; Perchard, J. P.; Zheng, W. Q. Rotational Isomerism of Ethanol and Matrix Isolation Infrared Spectroscopy. J. Phys. Chem. A 1998, 102, 5789-5793.

(11) Ritchie, G. L. D.; Watson, J. N.; Keir, R. I. Temperature Dependence of Electric Field-gradient Induced Birefringence (Buckingham Effect) and Molecular Quadrupole Moment of $\mathrm{N}_{2}$. Comparison of Experiment and Theory. Chem. Phys. Lett. 2003, 370, 376-380.

(12) Lee, J. J.; Höfener, S.; Klopper, W.; Wassermann, T. N.; Suhm, M. A. Origin of the Argon Nanocoating Shift in the OH Stretching Fundamental of $n$-Propanol: A Combined Experimental and Quantum Chemical Study. J. Phys. Chem. C 2009, 113, 10929-10938.

(13) Arean, C. O.; Delgado, M. R.; Nachtigall, P.; Thang, H. V.; Rubes, M.; Bulanek, R.; Chlubna-Eliasova, P. Measuring the Brønsted Acid Strength of Zeolites - Does it Correlate with the O-H Frequency Shift Probed by a Weak Base? Phys. Chem. Chem. Phys. 2014, 16, 10129-10141.

(14) Mahadevi, A. S.; Sastry, G. N. Cooperativity in Noncovalent Interactions. Chem. Rev. 2016, 116, 2775-2825.

(15) Coussan, S.; Loutellier, A.; Perchard, J. P.; Racine, S.; Bouteiller, Y. Matrix Isolation Infrared Spectroscopy and DFT Calculations of Complexes Between Water and Nitrogen. J. Mol. Struct. 1998, 471, 37-47.

(16) Emmeluth, C.; Dyczmons, V.; Suhm, M. A. Tuning the Hydrogen Bond Donor/Acceptor Isomerism in Jet-cooled Mixed Dimers of Aliphatic Alcohols. J. Phys. Chem. A 2006, 110, 2906-2915.

(17) Suhm, M. A. Hydrogen Bond Dynamics in Alcohol Clusters. Advances in Chemical Physics 2009, 142, 1-57.

(18) Coussan, S.; Alikhani, M. E.; Perchard, J. P.; Zheng, W. Q. Infrared-Induced Isomerization of Ethanol Dimers Trapped in Argon and Nitrogen Matrices: Monochromatic Irradiation Experiments and DFT Calculations. J. Phys. Chem. A 2000, 104, 5475-5483.

(19) Perchard, J. P.; Romain, F.; Bouteiller, Y. Determination of Vibrational Parameters of Methanol from Matrix-isolation Infrared Spectroscopy and Ab Initio Calculations. Part $1-$ Spectral Analysis in the Domain 11000-200 cm $\mathrm{cm}^{-1}$. Chem. Phys. 2008, 343, 35-46.

(20) Schriver, L.; Burneau, A.; Perchard, J. P. Infrared Spectrum of the Methanol Dimer in Matrices. Temperature and Irradiation Effects in Solid Nitrogen. J. Chem. Phys. 1982, 77, 4926-4932. 
(21) Murto, J.; Ovaska, M. Matrix Infrared Study of the Specific Interactions Between Methanol and Nitrogen, and Methanol and Carbon Monoxide. Spectrochim. Acta, Part A 1983, 39, 149-152.

(22) Coussan, S.; Loutellier, A.; Perchard, J. P.; Racine, S.; Peremans, A.; Tadjeddine, A.; Zheng, W. Q. IR-induced Interconversions Between Five Conformers of Methanol Dimers Trapped in Nitrogen Matrix. Chem. Phys. 1997, 223, 279-292.

(23) Korppi-Tommola, J. Association of Tert-Butyl Alcohol: A Matrix Infrared Study. J. Mol. Struct. 1977, 40, 13-23.

(24) Korppi-Tommola, J. Tert-Butyl Alcohol - Matrix I.R. Spectra and Vibrational Assignment. Spectrochim. Acta, Part A 1978, 34, 10771085 .

(25) Wassermann, T. N.; Suhm, M. A. Ethanol Monomers and Dimers Revisited: A Raman Study of Conformational Preferences and Argon Nanocoating Effects. J. Phys. Chem. A 2010, 114, 8223-8233.

(26) Provencal, R. A.; Paul, J. B.; Roth, K.; Chapo, C.; Casaes, R. N.; Saykally, R. J.; Tschumper, G. S.; Schaefer, H. F., III Infrared Cavity Ringdown Spectroscopy of Methanol Clusters: Single Donor Hydrogen Bonding. J. Chem. Phys. 1999, 110, 4258-4267.

(27) Han, H.-L.; Camacho, C.; Witek, H. A.; Lee, Y.-P. Infrared Absorption of Methanol Clusters $\left(\mathrm{CH}_{3} \mathrm{OH}\right)_{n}$ with $n=2-6$ Recorded with a Time-of-flight Mass Spectrometer Using Infrared Depletion and Vacuum-ultraviolet Ionization. J. Chem. Phys. 2011, 134, 144309.

(28) Zimmermann, D.; Häber, T.; Schaal, H.; Suhm, M. A. Hydrogen Bonded Rings, Chains and Lassos: The Case of t-Butyl Alcohol Clusters. Mol. Phys. 2001, 99, 413-425.

(29) Provencal, R. A.; Casaes, R. N.; Roth, K.; Paul, J. B.; Chapo, C. N.; Saykally, R. J.; Tschumper, G. S.; Schaefer, H. F. Hydrogen Bonding in Alcohol Clusters: A Comparative Study by Infrared Cavity Ringdown Laser Absorption Spectroscopy. J. Phys. Chem. A 2000, 104, $1423-1429$.

(30) Emmeluth, C.; Dyczmons, V.; Kinzel, T.; Botschwina, P.; Suhm, M. A.; Yanez, M. Combined Jet Relaxation and Quantum Chemical Study of the Pairing Preferences of Ethanol. Phys. Chem. Chem. Phys. 2005, 7, 991-997.

(31) Aldiyarov, A.; Aryutkina, M.; Drobyshev, A.; Kurnosov, V. IR Spectroscopy of Ethanol in Nitrogen Cryomatrices with Different Concentration Ratios. Low Temp. Phys. 2011, 37, 524-531.

(32) Zielke, P.; Suhm, M. A. Concerted Proton Motion in Hydrogenbonded Trimers: A Spontaneous Raman Scattering Perspective. Phys. Chem. Chem. Phys. 2006, 8, 2826-2830.

(33) Larsen, R. W.; Zielke, P.; Suhm, M. A. Hydrogen-bonded OH Stretching Modes of Methanol Clusters: A Combined IR and Raman Isotopomer Study. J. Chem. Phys. 2007, 126, 194307.

(34) Kjaergaard, H. G.; Robinson, T. W.; Howard, D. L.; Daniel, J. S.; Headrick, J. E.; Vaida, V. Complexes of Importance to the Absorption of Solar Radiation. J. Phys. Chem. A 2003, 107, 10680-10686.

(35) Suhm, M. A.; Kollipost, F. Femtisecond Single-mole Infrared Spectroscopy of Molecular Clusters. Phys. Chem. Chem. Phys. 2013, 15, 10702-10721.

(36) Omi, T.; Shitomi, H.; Sekiya, N.; Takazawa, K.; Fujii, M. Nonresonant Ionization Detected IR Spectroscopy for the Vibrational Study in a Supersonic Jet. Chem. Phys. Lett. 1996, 252, 287-293.

(37) Grimme, S.; Antony, J.; Ehrlich, S.; Krieg, H. A Consistent and Accurate $\mathrm{Ab}$ Initio Parametrization of Density Functional Dispersion Correction (DFT-D) for the 94 Elements H-Pu. J. Chem. Phys. 2010, $132,154104$.

(38) Frisch, M. J.; Trucks, G. W.; Schlegel, H. B.; Scuseria, G. E.; Robb, M. A.; Cheeseman, J. R.; Scalmani, G.; Barone, V.; Mennucci, B.; Petersson, G. A. et al. Gaussian 09; 2009.

(39) Grimme, S.; Ehrlich, S.; Goerigk, L. Effect of the Damping Function in Dispersion Corrected Density Functional Theory. J. Comput. Chem. 2011, 32, 1456-1465.

(40) Bloino, J.; Barone, V. A Second-order Perturbation Theory Route to Vibrational Averages and Transition Properties of Molecules: General Formulation and Application to Infrared and Vibrational Circular Dichroism Spectroscopies. J. Chem. Phys. 2012, 136, 124108.
(41) Werner, H.-J.; Knowles, P. J.; Knizia, G.; Manby, F. R.; Schütz, M. Molpro: A General-purpose Quantum Chemistry Program Package. WIREs Comput. Mol. Sci. 2012, 2, 242-253.

(42) Tew, D. P.; Klopper, W.; Heckert, M.; Gauss, J. Basis Set Limit $\operatorname{CCSD}(\mathrm{T})$ Harmonic Vibrational Frequencies. J. Phys. Chem. A 2007, $111,11242-11248$.

(43) Bendtsen, J.; Rasmussen, F. High-resolution Incoherent Fourier Transform Raman Spectrum of the Fundamental Band of ${ }^{14} \mathrm{~N}_{2}$.J. Raman Spectrosc. 2000, 31, 433-438.

(44) Martínez, R. Z.; Bermejo, D. High-resolution Stimulated Raman Study of the First Vibrational Hot Band of ${ }^{14} \mathrm{~N}_{2}$. Separate Observation of the Spectra of the Ortho and Para Species. J. Raman Spectrosc. 2013, 44, 727-730.

(45) Heger, M.; Suhm, M. A.; Mata, R. A. Communication: Towards the Binding Energy and Vibrational Red Shift of the Simplest Organic Hydrogen Bond: Harmonic Constraints for Methanol Dimer. J. Chem. Phys. 2014, 141, 101105.

(46) Heger, M.; Andersen, J.; Suhm, M. A.; Wugt Larsen, R. The Donor OH Stretching-libration Dynamics of Hydrogen-bonded Methanol Dimers in Cryogenic Matrices. Phys. Chem. Chem. Phys. 2016, 18, 3739-3745.

(47) Dyczmons, V. Dimers of Ethanol. J. Phys. Chem. A 2004, 108, 2080-2086.

(48) Loru, D.; Peña, I.; Sanz, M. E. Ethanol Dimer: Observation of Three New Conformers by Broadband Rotational Spectroscopy. J. Mol. Spectrosc. 2017, DOI: 10.1016/j.jms.2017.03.007.

(49) Hearn, J. P. I.; Cobley, R. V.; Howard, B. J. High-resolution Spectroscopy of Induced Chiral Dimers: A Study of the Dimers of Ethanol by Fourier Transform Microwave Spectroscopy. J. Chem. Phys. 2005, 123, 134324.

(50) Maris, A.; Caminati, W.; Velino, B.; Andrews, C. M.; Howard, B. J. Free and Pulsed Jet Rotational Spectra and van der Waals Motions

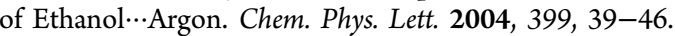

(51) Heger, M. Diagonal and Off-Diagonal Anharmonicity in Hydrogen-Bonded Systems. Ph.D. thesis, Georg-August-University: Göttingen, Germany, 2016.

(52) MacLeod, K. C.; McWilliams, S. F.; Mercado, B. Q.; Holland, P. L. Stepwise N-H Bond Formation From $\mathrm{N}_{2}$-Derived Iron Nitride, Imide and Amide Intermediates to Ammonia. Chem. Sci. 2016, 7, $5736-5746$

(53) Himmel, H.-J.; Reiher, M. Intrinsic Dinitrogen Activation at Bare Metal Atoms. Angew. Chem., Int. Ed. 2006, 45, 6264-6288.

(54) Rowland, B.; Fisher, M.; Devlin, J. P. Probing Icy Surfaces with the Dangling-OH-mode Absorption: Large Ice Clusters and Microporous Amorphous Ice. J. Chem. Phys. 1991, 95, 1378-1384.

(55) Andrews, L.; Davis, S. R. FTIR Observation of N $\equiv N$ Stretching Fundamentals in Hydrogen-bonded Complexes in Solid Argon. J. Chem. Phys. 1985, 83, 4983-4989.

(56) Kollipost, F.; Andersen, J.; Mahler, D. W.; Heimdal, J.; Heger, M.; Suhm, M. A.; Wugt Larsen, R. The Effect of Hydrogen Bonding on Torsional Dynamics: A Combined Far-infrared Jet and Matrix Isolation Study of Methanol Dimer. J. Chem. Phys. 2014, 141, 174314. 